\title{
Epithelial-to-mesenchymal transition in FHC-silenced cells: the role of CXCR4/ CXCL12 axis
}

\author{
I. Aversa ${ }^{1 \dagger}$, F. Zolea ${ }^{1 \dagger}$, C. leranò ${ }^{2}$, S. Bulotta ${ }^{3}$, A. M. Trotta ${ }^{2}$, M. C. Faniello ${ }^{1}$, C. De Marco ${ }^{4}$, D. Malanga ${ }^{4}$, F. Biamonte ${ }^{1}$, \\ G. Viglietto ${ }^{4}$, G. Cuda ${ }^{1 *}$, S. Scala ${ }^{2+}$ and F. Costanzo ${ }^{1+}$
}

\begin{abstract}
Background: Ferritin plays a central role in the intracellular iron metabolism; the molecule is a nanocage of 24 subunits of the heavy and light types. The heavy subunit (FHC) is provided of a ferroxidase activity and thus performs the key transformation of iron in a non-toxic form. Recently, it has been shown that FHC is also involved in additional not iron-related critical pathways including, among the others, p53 regulation, modulation of oncomiRNAs expression and chemokine signalling. Epithelial to mesenchymal transition (EMT) is a cellular mechanism by which the cell acquires a fibroblast-like phenotype along with a decreased adhesion and augmented motility. In this work we have focused our attention on the role of the FHC on EMT induction in the human cell lines MCF-7 and H460 to elucidate the underlying molecular mechanisms.

Methods: Targeted silencing of the FHC was performed by lentiviral-driven shRNA strategy. Reconstitution of the FHC gene product was obtained by full length FHC cDNA transfection with Lipofectamine 2000. MTT and cell count assays were used to evaluate cell viability and proliferation; cell migration capability was assayed by the wound-healing assay and transwell strategy. Quantification of the CXCR4 surface expression was performed by flow cytometry.

Results: Experimental data indicated that FHC-silenced MCF-7 and H460 cells (MCF- $7^{\text {shFHC }}$, H460 $0^{\text {shFHC }}$ ) acquire a mesenchymal phenotype, accompanied by a significant enhancement of their migratory and proliferative capacity. This shift is coupled to an increase in ROS production and by an activation of the CXCR4/CXCL12 signalling pathway. We present experimental data indicating that the cytosolic increase in ROS levels is responsible for the enhanced proliferation of FHC-silenced cells, while the higher migration rate is attributable to a dysregulation of the CXCR4/CXCL12 axis.

Conclusions: Our findings indicate that induction of EMT, increased migration and survival depend, in MCF-7 and H460 cells, on the release of FHC control on two pathways, namely the iron/ROS metabolism and CXCR4/CXCL12 axis. Besides constituting a further confirmation of the multifunctional nature of FHC, this data also suggest that the analysis of FHC amount/function might be an important additional tool to predict tumor aggressiveness.
\end{abstract}

Keywords: Ferritin heavy chain, EMT, CXCR4, CXCL12, Cancer, ROS

\footnotetext{
*Correspondence: cuda@unicz.it

${ }^{\dagger}$ Equal contributors

${ }^{1}$ Research Center of Advanced Biochemistry and Molecular Biology,

Department of Experimental and Clinical Medicine, Magna Græcia University

of Catanzaro, Salvatore Venuta Campus, Viale Europa, 88100 Catanzaro, Italy

Full list of author information is available at the end of the article
} 


\section{Background}

Epithelial to mesenchymal transition (EMT) is a rapid and often reversible phenomenon characterized by morphological changes of epithelial cells. The activation of the EMT process leads to cytoskeleton re-organization, loss of cell-cell adhesion molecules, modification of cellular polarization, de novo expression of mesenchymal proteins and acquisition of stemness properties [1, 2]. Thus, the cells undergoing EMT gain increased cell motility, invasive properties and resistance to anoikis $[3,4]$. EMT plays a role in normal development, such as heart morphogenesis and neural crest formation [5]. However, the acquisition of a mesenchymal phenotype makes cancer cells more aggressive and metastatic, therefore suggesting that EMT might be considered as an attractive therapeutic target [6-8].

A variety of studies performed both in vitro and in vivo have focused on the identification of EMT-inducing agents, underscoring, among others, the role played by the reactive species of oxygen (ROS), hypoxia and perturbations of the intracellular iron metabolism $[9,10]$. Ferritin, a globular protein of $450 \mathrm{kDa}$, is the major iron storage protein within the cell, thus playing a central role in the maintenance of redox homeostasis [11]. Ferritin is present in cytoplasm, nucleus and mitochondria; the cytoplasmic form is composed by 24 subunits of heavy (FTH, FHC) and light type (FTL), assembled to form a central cavity where the iron atoms are stored [11]. FHC and FTL share an extensive homology in the sequence but perform different functions in iron metabolism: FHC holds a ferroxidase activity and is devoted to rapid iron uptake and release, while FTL contributes to the long-term iron storage [12]. The enzymatic activity held by FHC makes it a key molecule in the control of the intracellular free iron and, as a consequence, of ROS production; therefore it has been hypothesized, and demonstrated in given cell types, a role for FHC in EMT induction [10].

Besides iron metabolism, FHC controls additional biochemical pathways such as cell proliferation [13], p53 regulation [14], chemokine signalling [15], angiogenesis [16], regulation of oncomiRNAs network [17], control of proper protein folding [18], stem cell expansion [19]. In some pathways FHC physically interacts with target molecules independently from its ferroxidase activity [19]. Among the molecules whose activity is modulated upon FHC binding there is the chemokine receptor CXCR4 [15]. CXCR4 is a seven-span transmembrane G proteincoupled receptor (GPCR) that binds the Stromal-Derived Factor-1 (SDF-1 or CXCL12) ligand [20]. CXCR4 is widely expressed in different tissues, where it plays a central role in development-related processes; deficit of the CXCR4/ CXCL12 axis determines severe alterations of the hematopoietic, immune and CNS compartments [21].
Moreover, CXCR4 expression is increased in a variety of human cancers [22-25] where it regulates tumor progression and EMT [26-28].

In this paper we provide evidence that $\mathrm{FHC}$ silencing in the human breast cancer MCF-7 and in the lung adenocarcinoma H460 cells induces EMT and enhances proliferative and migratory abilities. In these cell lines, FHC knock down is accompanied by an increase in ROS content and by an approximately two-fold increase of CXCR4 receptor expression, along with a strong activation of its downstream pathways. ROS increase largely contributes to the higher proliferation rate of $\mathrm{FHC}$ silenced cells, while their enhanced migratory ability is mainly ascribable to the activated CXCR4/CXCL12 axis.

The data presented here add new insights into the role of FHC in transformed cells, indicating that perturbations of its intracellular content are accompanied by an up-regulation of the CXCR4/CXCL12 axis, which, in turn, contributes to the acquisition of a more aggressive phenotype.

\section{Methods \\ Cell cultures}

MCF-7 human breast adenocarcinoma cells (ATCC, Manassas, VA, USA) were cultured in DMEM (SigmaAldrich, St. Louis, MO, USA) medium supplemented with $10 \%$ fetal bovine serum (FBS) and 1\% PenicillinStreptomycin (Sigma-Aldrich); H460 human non-small lung cancer cell (ATCC) were cultured in RPMI 1640 (Sigma-Aldrich) medium supplemented with 10\% fetal bovine serum (FBS) and 1\% Penicillin-Streptomycin (Sigma-Aldrich). The two cell lines were maintained at $37{ }^{\circ} \mathrm{C}$ in a humidified 5\% CO2 atmosphere. HEK-293 T cells (Sigma-Aldrich) were cultured in adherent conditions in DMEM (Sigma-Aldrich) medium with 10\% FBS and $1 \%$ Penicillin-Streptomycin at $37{ }^{\circ} \mathrm{C}$ in a humidified $5 \% \mathrm{CO} 2$ atmosphere.

\section{Preparation of lentiviral supernatants and transduction of MCF-7 and H460 cells}

Lentiviral preparation and transduction were performed as described in Di Sanzo et al. [29]. Cells were stably transduced with a lentiviral DNA containing either an shRNA that targets the 196-210 region of the FHC mRNA (sh29432) $\left(\mathrm{MCF}-7^{\text {shFHC }}\right)\left(\mathrm{H} 460^{\text {shFHC }}\right)$ or a control shRNA without significant homology to known human mRNAs $\left(\mathrm{MCF}-7^{\text {shRNA }}\right)\left(\mathrm{H} 460^{\text {shRNA }}\right)$. A pool of clones were analysed after puromycin selection.

\section{FHC reconstitution}

MCF- $7^{\text {shFHC }}$ cells were seeded in six-well plates at $6 \times 10^{5}$ cells/well and grown overnight prior to transfection. All plasmids were transfected with Lipofectamine 
2000 transfection reagent (Thermo Fisher Scientific, Waltham, MA, USA) following manufacturer's instructions.

FHC reconstitution was performed using $2 \mu \mathrm{g} / \mu \mathrm{l}$ of the expression vector containing the full length of human FHC cDNA $\left(\mathrm{pcDNA}_{3} / \mathrm{FHC}\right) \quad\left(\mathrm{MCF}-7^{\text {shFHC/pcDNA }}{ }_{3}{ }^{\mathrm{FHC}}\right)$ while $2 \mu \mathrm{g} / \mu \mathrm{l}$ of $\mathrm{pcDNA}_{3}$ plasmid was used as negative control $\left(\mathrm{MCF}-7^{\mathrm{shFHC} / \mathrm{pCDNA}_{3}}\right)$. Transfection efficiency was tested $48 \mathrm{~h}$. All transfection experiments were repeated in triplicate.

\section{RNA extraction and semi-quantitative reverse transcriptase} polymerase chain reaction (RT-PCR)

Total RNA was extracted from FHC-silenced MCF-7 and $\mathrm{H} 460$ (MCF-7 $7^{\text {shFHC }}, \mathrm{H}_{4} 60^{\text {shFHC }}$ ) and scrambledshRNA MCF-7 and H460 (MCF-7 ${ }^{\text {shRNA }}, \mathrm{H}_{460} 0^{\text {shRNA }}$ ) by using Trizol method according to the manufacturer's instructions (Thermo Fisher Scientific). All the RNA samples were DNase-1 treated (Ambion, Austin, TX, USA), and purity and integrity of the RNA was checked spectroscopically and by gel electrophoresis before use. Then, $1 \mu \mathrm{g}$ of purified RNA was reverse-transcribed by using High capacity cDNA Reverse Transcription kit (Thermo Fisher Scientific) [30].

\section{Western blotting analysis}

MCF-7 and H460 silenced and un-silenced cells were lysed in the following buffer $(20 \mathrm{mM}$ Hepes $\mathrm{pH} 7.9$, $420 \mathrm{mM} \mathrm{NaCl}, 1 \%$ Triton $\times-100,1 \mathrm{mM}$ EDTA, 25\% glycerol, $1 \mathrm{mM}$ PMSF, $1 \mathrm{mM} \mathrm{Na} \mathrm{VO}_{4}, 1 \mathrm{mM}$ DTT, $1 \mu \mathrm{g} / \mathrm{ml}$ aprotinin, $1 \mu \mathrm{g} / \mathrm{ml}$ leupeptin) for $30 \mathrm{~min}$ on ice. After removing cell debris by centrifugation $(12,000 \mathrm{~g} \times 30 \mathrm{~min})$, the concentration of protein extracts was measured by the Bio-Rad protein assay according to the manufacturer's instructions (BioRad, California, USA). Total protein extract was boiled for $10 \mathrm{~min}$ in SDS sample buffer, separated by $10-12 \%$ SDS-PAGE and transferred to a nitrocellulose membrane by electroblotting. Non-specific reactivity was blocked in nonfat dry milk in TPBS [5\% $(w / v)$ milk in PBS $(\mathrm{pH}$ 7.4) and $0.005 \%$ Tween 20] for $2 \mathrm{~h}$ at room temperature. The membrane was incubated with rabbit anti-H ferritin (1:200; Santa Cruz Biotechnology, Texas, USA), rabbit anti-CXCR4 antibody (1:500; Abcam, Cambridge, UK), rabbit anti-VIMENTIN, anti-E-CADHERIN antibodies, anti-phospho-AKT (Ser473), anti-AKT, antiP70S6 K, anti-phospho-P70S6 K (T389) (1:1000; Cell Signaling Technology, Danvers, MA, USA) over-night at $4{ }^{\circ} \mathrm{C}$, followed by incubation with goat anti-rabbit secondary antibody (1:5000; Santa Cruz Biotechnology). The membrane was developed by ECL-Western blot detection reagents according to the manufacturer's instructions (Santa Cruz Biotechnology). $\gamma$-Tubulin was used as a loading control.

\section{Quantitative real-time PCR (qRT-PCR)}

Gene expression analysis was assessed by real-time PCR using the cDNA obtained from MCF- $7^{\text {shRNA }}$, MCF$7^{\text {shFHC }}$, MCF- $73^{\text {shFHC/pcDNAFHC }}$ and from $\mathrm{H} 460^{\text {shRNA }}$ and $\mathrm{H} 460^{\text {shFHC }}$ cells.

Primer sequences used for amplifications were as follows:

GAPDH-F 5 '-aac acc acc atg gag aag gc $-3^{\prime}$; GAPDH-R 5 '-aca gcc ttg gca gca cca ct-3';

FHC FW: 5'-cat caa ccg cca gat caa c-3'; FHC REV: 5' gat ggc ttt cac ctg ctc at- $3^{\prime}$.

Twist-F $5^{\prime}$-tga atc ttg ctc agc ttg tc-3'; Twist-R $5^{\prime}$-cgg gcg tcc gga gtc tta-3';

Slug-F 5 '-ggt gtc aga tgg agg agg g-3'; Slug-R $5^{\prime}$-cat gcc tgt cat acc aca ac-3';

Vim-F 5'-agg aaa tgg ctc gtc acc ttc gtg-3' Vim-R 5'gga gtg tcg gtt gtt aag aac tag-3';

E-cadherin-F $5^{\prime}$-tac gcc ggg act cca cct a-3'; Ecadherin-R $5^{\prime}$-cca gaa agc gag gcc tga $t-3$ '.

$20 \mathrm{ng}$ of cDNA was amplified in $20 \mu \mathrm{l}$ of reaction mix containing Power SYBR Green PCR Master mix (Thermo Fisher Scientific), 20 pmol of each primer pair and nuclease-free water. The thermal profile consisted of 1 cycle at $95{ }^{\circ} \mathrm{C}$ for 10 min followed by 40 cycles at $95{ }^{\circ} \mathrm{C}$ for $15 \mathrm{~s}, 60{ }^{\circ} \mathrm{C}$ for $1 \mathrm{~min}$. The human GAPDH cDNA fragment was amplified as the internal control. Data analysis was performed using the $2^{-\Delta \Delta \mathrm{Ct}}$ [31].

\section{Immunofluorescence}

MCF-7 and H460 cells were cultured on cover slip. After two wash in PBS, cells were fixed with $4 \%$ paraformaldehyde (PFA) (Sigma Aldrich) in Sodium Posphate solution $0.120 \mathrm{M} \mathrm{pH}=7.4$, for $20 \mathrm{~min}$ at $37^{\circ} \mathrm{C}$ and then washed in PBS. Cells were washed twice with high salt solution (HS: $\mathrm{NaCl} 500 \mathrm{mM}, \mathrm{Na}_{3} \mathrm{PO}_{4} \mathrm{pH}=7.420 \mathrm{mM}$ ) and then permeabilized in HS buffer containing Triton$\mathrm{X}-100 \quad 0.3 \%$ and jelly at $0.2 \%$ for $30 \mathrm{~min}$ at room temperature in a humidified room. To stain actin filaments, cells were incubated for $30 \mathrm{~min}$ in this buffer containing Oregon Green ${ }^{\circ} 488$ phalloidin at 1:400 dilution (Molecular Probes, Thermo Fisher Scientific), while primary antibodies (ferritin heavy chain, 1:100 Santa Cruz Biotechnology; Vimentin and E-Cadherin, 1:100, Cell Signaling) were diluted in the same buffer for $2 \mathrm{~h}$ at room temperature. Appropriate secondary antibodies (antimouse IgG Alexa Fluor 488 and anti-rabbit IgG Alexa Fluor 555, Thermo Fisher Scientific) diluted in HS buffer were applied for $1 \mathrm{~h}$ at room temperature. After 3 washes with HS buffer and 1 wash with PBS, Nuclear Dapi (1:1000, Invitrogen, Carlsbad, CA) was added for 20 min (ProLong Gold antifade Reagent, Molecular Probes, Eugene, OR). The slides were mounted on microscope slides using a mounting solution ProLong Gold antifade reagent (Thermo Fisher Scientific). Images 
were collected using a Leica DM-IRB/TC-SP2 confocal microscopy system $(40 \times, 63 \times$ or $100 \times$ objective $)$ at $1024 \times 1024$ resolution pixel.

\section{ROS detection}

ROS were determined by incubating MCF-7 and H460 silenced and unsilenced cells with the redox-sensitive probe 2'-7'-DCF (CM-H2CFDA; Molecular Probes, Eugene, OR) [32]. Briefly, $1 \times 10^{6}$ cells were plated in 96well plates and incubated with Hanks balanced saline solution (HBSS), $10 \mathrm{mM}$ glucose and $20 \mu \mathrm{m}$ DCF for 15 min at $37^{\circ} \mathrm{C}$. After two cycle washes, cells were maintained in HBSS supplemented with $10 \mathrm{mM}$ glucose. Fluorescence was measured using the FACS FORTESSA.

\section{Cell viability and proliferation assays}

Cell viability was tested using a 3-(4,5-dimethylthiazol2-yl)-2, 5-diphenyl tetrazolium bromide (MTT) (SigmaAldrich) assay. For the assay, $3 \times 10^{3} \mathrm{FHC}$-silenced and unsilenced MCF-7 and H460 cells were plated in 96well flat bottom tissue culture plate. At 24,48 and $72 \mathrm{~h}$ of culture, $10 \mu \mathrm{l}$ of MTT solution $(2 \mathrm{mg} / \mathrm{mL})$ were added per well. After $6 \mathrm{~h}$ of incubation crystals of formazan were solubilized with $50 \mu \mathrm{l}$ of 2-Propanol (Sigma-Aldrich). Optical density (O.D.) was read on a multiwell scanning spectrophotometer (ELISA reader) at 450 and $595 \mathrm{~nm}$.

To assess cell proliferation MCF-7 and H460 cells were plated in DMEM and RPMI complete media. Cell counts using trypan blue were performed at $0,24,48$ and $72 \mathrm{~h}$.

\section{Glucose and lactate assay}

MCF-7 and H460 cells $\left(1 \times 10^{5}\right)$ were seeded in $10 \mathrm{ml}$ of DMEM (MCF-7) or RPMI 1640 (H460) (Sigma-Aldrich), supplemented with FBS and Penicillin-Streptomycin (Sigma-Aldrich) in $100 \mathrm{~mm}$ plates. After 24, 48, 72 and $96 \mathrm{~h}, 500 \mu \mathrm{l}$ of supernatant were taken and glucose and lactate concentration was measured using COBAS 6000 instrument (Roche, Indianapolis, IN, USA). The assay was performed three times.

\section{Wound healing assay}

MCF-7 and H460 cells were seeded in a 6-well plates and cultured until reaching confluence. For simulating a wound, a (yellow) pipette tip was used to make a scratch. At 0,24 and $48 \mathrm{~h}$, cells were monitored and images of wound healing were captured (magnification of 10X) using the Leica DFC420 C and Leica Application Suite Software. Subsequently, cell migration was quantified by measuring the wound opening area with ImageJ64 software.

\section{Quantification of CXCR4 surface expression}

MCF-7 and H460 cells $\left(1 \times 10^{6}\right)$ were harvested and rinsed twice, and $1 \%$ bovine serum albumin (BSA) in PBS solution was used to block the cells for $30 \mathrm{~min}$ in an ice bath. Then cells were stained with anti-CXCR4 PE-antibody (FAB170P, clone 12G5, R\&D Systems, Minneapolis, MN, USA) for $1 \mathrm{~h}$ at $4{ }^{\circ} \mathrm{C}$. After antibody staining, cells were rinsed with $1 \%$ BSA in PBS three times, resuspended in PBS, and evaluated by a FACS Canto II cytofluorometer (Becton Dickinson Immunocytometry Systems, Mountain View, CA, USA).

\section{Migration assay}

Migration was assayed in 24 transwell chambers (Corning Inc., Corning, NY, USA) using inserts with $8-\mu \mathrm{m}$ pore membrane. MCF-7 and H460 cells were placed in the upper chamber $\left(2 \times 10^{5}\right.$ cells/well $)$ in DMEM containing 0.5\% BSA (migration media) plus/minus AMD3100. CXCL12 (100 ng/mL) was added to the lower chamber. After $18 \mathrm{~h}$ of incubation, cells on the upper surface of the filter were removed using a cotton wool swab; the cells that had migrated onto the lower surface of the membrane were stained with DAPI, photographed and visually counted in 10 random fields. Migration index is the ratio between number of migrated cells / number of migrating cells toward CXCL12 free media [33].

\section{cAMP assay}

MCF- $7^{\text {shRNA }}$ and MCF- $7^{\text {shFHC }}$ cells were pre-incubated for $30 \mathrm{~min}$ at $37^{\circ} \mathrm{C}$ with AMD3100 $(10 \mu \mathrm{M})$. Subsequently forskolin $(1 \mu \mathrm{M})$ for 20 min was added and stimulation with CXCL12 (100 ng/ml) for $10 \mathrm{~min}$ was done. Controls include cells stimulated with CXCL12 and forskolin, or forskolin alone in absence of anti-CXCR4 inhibitors. Then the cells were harvested and lysed with $0.1 \mathrm{M} \mathrm{HCl}$ and cAMP levels was assayed using a direct competitive enzyme immunoassay (BioVision, Milpitas, CA, USA).

\section{Statistical analysis}

Data are expressed as means \pm SD of at least three independent experiments conducted in triplicates as indicated in the text and in the figure legends. Statistical significance was evaluated by $t$-test or Two-way ANOVA as indicated in the figure legends. Statistical significance was indicated as follows: $p \leq 0.05\left(^{(*)}, p \leq 0.01{ }^{(* *)}\right.$, $p \leq 0.001\left(^{* * * *)}\right.$ and $p \leq 0.0001\left(^{* * * * *)}\right.$.

\section{Results}

Silencing of $\mathrm{H}$ ferritin triggers EMT in MCF-7 cells

We previously demonstrated that $\mathrm{FHC}$ intracellular amounts may regulate the expression of a number of miRNAs and EMT-related genes (miR-125b, Vimentin, and SPARC) in different cell types [17, 19, 34]. In this work, we evaluated the effects of FHC silencing on EMT 
in MCF-7 human breast cancer cells and in H460 human lung cancer cells. MCF-7 cells were stably transduced with a lentiviral DNA containing a Hferritin specific shRNA (MCF- $7^{\text {shFHC }}$ ) or with an shRNA without significant homology to known human mRNAs (MCF-7 $\left.{ }^{\text {shRNA }}\right)$. FHC mRNA and protein levels were measured in pools of silenced clones, as illustrated in Panel a of Fig. 1. Panel b shows a representative immunofluorescence for $\mathrm{H}$ ferritin subunit in MCF-7 ${ }^{\text {shFHC }}$ and MCF-7 $7^{\text {shRNA }}$ cells.

FHC silencing produced dramatic morphological changes in MCF-7 cells. Indeed, phase-contrast microscope analysis revealed that the $\mathrm{MCF}-7^{\text {shFHC }}$ cells underwent a consistent modification, passing from a cobblestone-like morphology to a spindleshaped and fusiform features (Panel $\mathrm{C}$ of Fig. 1), as well as cytoskeleton disarray, shown by staining of actin filaments with phalloidin (Panel D of Fig. 1). To corroborate the morphological data, we analysed the expression of several EMT markers in the MCF$7^{\text {shFHC }}$ and MCF- $7^{\text {shRNA }}$ cells. Western blot, immunofluorescence and GPCR, reported in Fig. 2, show that FHC-silencing is accompanied by a decreased expression of E-cadherin, by an increase of Vimentin and by an up-regulation of EMT-related transcription factors Twist, Slug and ZEB1 [35-37].

To strengthen the relationship between FHC downregulation and EMT induction, we rescued $\mathrm{FHC}$ expression in MCF- $7^{\text {shFHC }}$ cells (Fig. 3, Panel A), and re-evaluated the EMT markers. As shown in Panel B of Fig. 3, the expression of Vimentin, Twist and Slug was consistently reduced upon FHC reconstitution, while E-Cadherin levels were unaffected. We believe that this last phenomenon may be determined by the fact that the partial rescue of Twist and
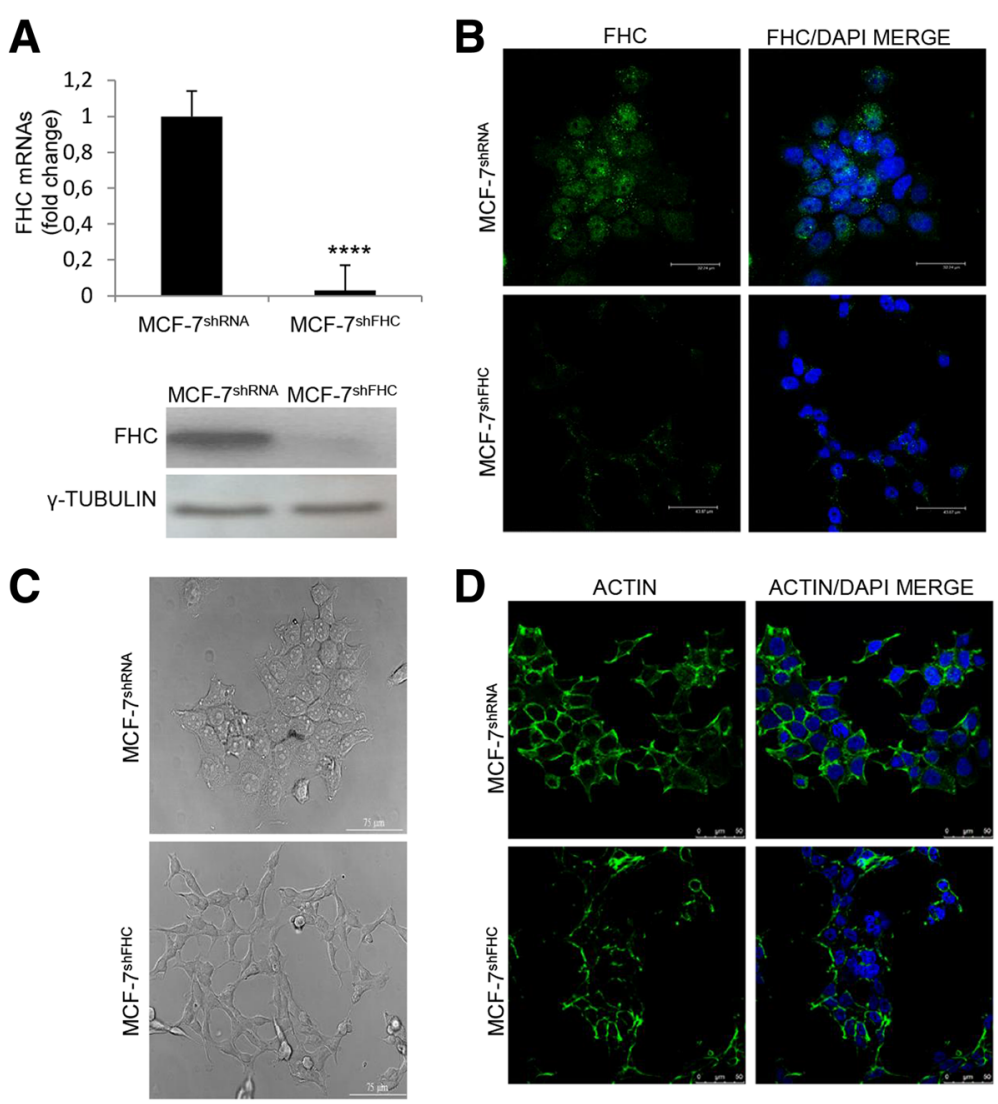

Fig. $1 \mathrm{H}$ ferritin gene silencing in MCF-7 cells. a Real-time PCR analysis of FHC mRNA expression was performed on total RNA extracted from MCF-7 ${ }^{\text {shRNA }}$ and MCF-7 $7^{\text {ShFHC }}$ cells. Final results represent mean \pm SD of three independent experiments. Statistical significance was evaluated by Student t-test (****,$p<0.0001$ ). Western Blot analysis for FHC expression was performed on $50 \mu \mathrm{g}$ of total protein extracts from MCF-7 ${ }^{\text {shRNA }}$ and MCF-7 $7^{\text {shFHC }}$ cells. $\gamma^{-T u b u l i n}$ was used as loading control. Representative data from one of three experiments. $\mathbf{b}$ MCF- $7^{\text {shRNA }}$ and MCF-7 $7^{\text {shFHC }}$ cells were fixed and incubated with monoclonal anti-FHC antibody (1:200) followed by incubation with the appropriate secondary antibody. Nuclei were visualized by DAPI staining. Images were collected using a Leica TCS SP2 confocal microscopy system (63X). Representative data from one of three experiments. c Images, collected using the phase-contrast microscope (Leica DMI 6000 CS), were used to highlight morphological changes between MCF-7 $7^{\text {shRNA }}$ and MCF-7 $7^{\text {shFHC }}$ cells. Representative data from one of three experiments. $\mathbf{d}$ MCF- $7^{\text {shRNA }}$ and MCF-7 $7^{\text {shFHC }}$ cells were fixed and incubated with Oregon Green 488 phalloidin (1:400) to visualize actin filaments. Nuclei were visualized by DAPI staining. Images were collected using confocal microscopy system (40X). Representative data from one of three experiments 
A
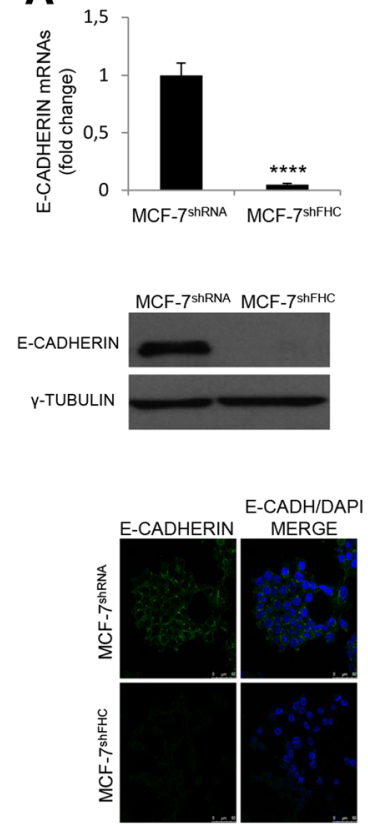
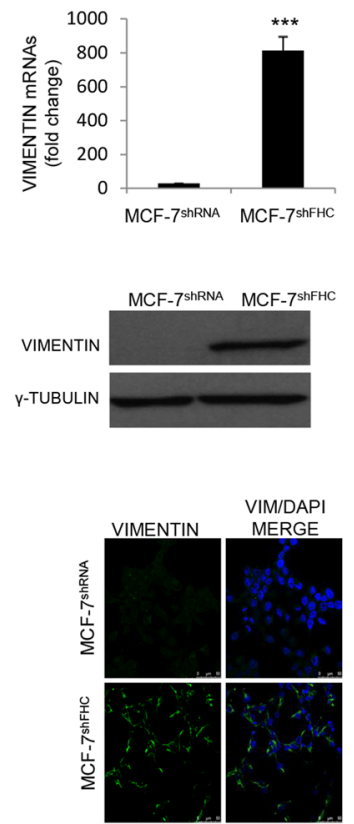

B

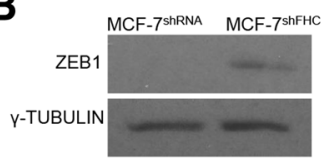

C
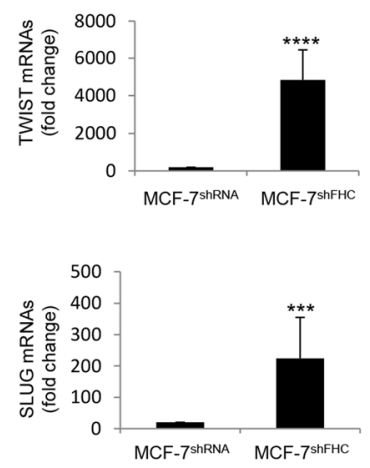

MCF-7

Fig. 2 FHC-silencing and EMT gene expression in MCF7 cells. a E-Cadherin and Vimentin expression were evaluated by Real-time PCR, Western Blot and Immunofluorescence analysis. Real-time PCR were performed on total RNA extracted from MCF-7 ${ }^{\text {shRNA }}$ and MCF- $7^{\text {shFHC }}$ cells. Final results represent mean \pm SD of three independent experiments. Statistical significance was evaluated by Student t-test $\left(* * *, p<0.001,{ }^{* * * *}, p<0.0001\right)$. Western Blot analysis were performed on $50 \mu \mathrm{g}$ of total protein extract from MCF-7 $7^{\text {shRNA }}$ and MCF-7 $7^{\text {shFHC }}$ cells. $\gamma^{-T u b u l i n}$ was used as loading control. For the Immunofluorescence analysis MCF- - $^{\text {hhNNA }}$ and MCF- $7^{\text {shFHC }}$ cells were fixed and incubated with polyclonal anti-E-Cadherin or anti-Vimentin antibody (1:100) followed by incubation with the appropriate secondary antibody. Nuclei were visualized by DAPI staining. Images were collected using a Leica TCS SP2 confocal microscopy system (63X). Images are representative data from one of three experiments. $\mathbf{b}$ Western Blot analysis of

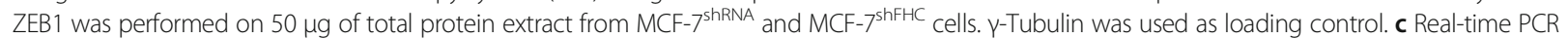
for Twist and Slug were performed on total RNA extracted from MCF- $7^{\text {shRNA }}$ and MCF-7 $7^{\text {shFHC }}$ cells. Final results represent mean \pm SD of three independent experiments. Statistical significance was evaluated by Student t-test (**, $p<0.001$ )

Slug in transiently FHC-reconstituted MCF-7 cells is still able to efficiently repress the expression of E-Cadherin. This hypothesis is confirmed by several published data reporting that the transcriptional regulation is indeed the major mechanism controlling E-Cadherin expression [35, 36].

\section{MCF7 $^{\text {shFHC }}$ cells display enhanced mobility, higher growth- and metabolic-rate}

Epithelial cells undergoing EMT lose cell polarity and cell-to-cell adhesion capability, acquiring, in turn, enhanced migratory and invasive properties [37]. To further investigate the effects of FHC-silencing, we performed a wound healing assay on MCF-7 $7^{\text {shFHC }}$ and control cells. The results of a triplicate set of independent assays (Panel A of Fig. 4) demonstrate that the MCF- $7^{\text {shFHC }}$ cells possess, at $48 \mathrm{~h}$, an enhanced migratory capability consistent with their EMT phenotype.

Next, we evaluated by methyl-thiazolyl-tetrazolium (MTT) assay the viability of FHC-silenced cells at 24, 48 and $72 \mathrm{~h}$. The results, shown in Panel B of Fig. 4, indicate that FHC silencing increased cell proliferation with a maximum of about 1.8-fold at $72 \mathrm{~h}$. Moreover, as further feature of cellular aggressiveness, the glucose/lactate levels were quantified over time in the $M C F 7^{\text {shFHC }}$ versus $\mathrm{MCF}^{\text {shRNA }}$ cells. A time-dependent decrease in glucose concentration, paralleled by an increase in lactate levels were detected in the culture medium of MCF- $7^{\text {shFHC }}$, indicating that the MCF-7 ${ }^{\text {shFHC }}$ cells are indeed consuming higher amounts of glucose for energy production (Panel C of Fig. 4).

\section{The ROS scavenger $\mathrm{N}$-acetylcysteine (NAC) partially rescued EMT in MCF- $7^{\text {shFHC }}$}

Down-regulation of ferritin, and particularly of its heavy subunit, determines an increase of the intracellular Labile Iron Pool (LIP) [38-41]. The free iron, in turn, induces the formation of Reactive Oxygen Species (ROS), which are implicated in EMT induction in different cell types [10, 42, 43]. Panel A of Fig. 5 shows that, in MCF$7^{\text {shFHC }}$ cells, ROS amount is about five-fold greater than that in MCF- $7^{\text {shRNA }}$ cells. To investigate to what extent increased ROS are related to EMT in our experimental 


\section{A}

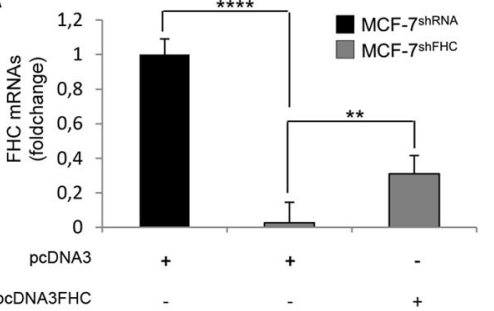

MCF-7

B
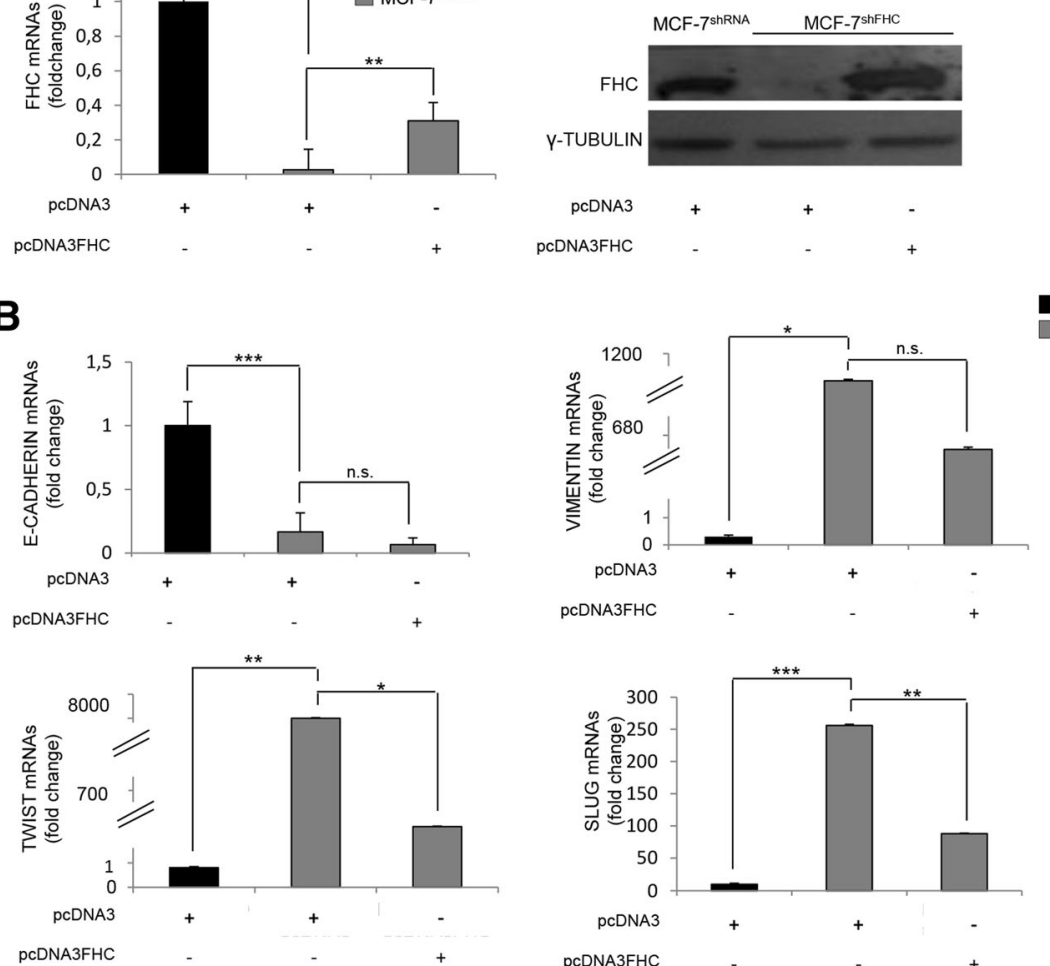

MCF-7 $7^{\text {ShRNA }}$

MCF-7 $7^{\text {shFHC }}$

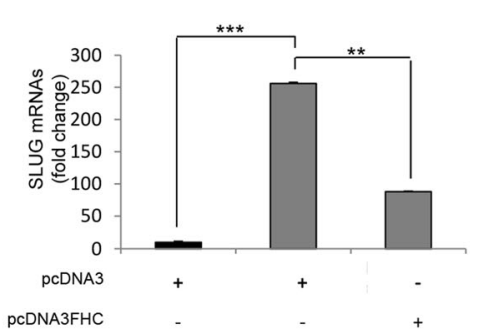

Fig. 3 EMT markers and FHC amounts in MCF-7 cells. a Real-time PCR analysis of FHC was performed on total RNA extracted from MCF-7 shRNA $^{2}$ pcDNA ${ }_{3}, M_{C F} 7_{3}^{\text {shFHC/PCDNA }}$ and MCF-73 shHC/PcDNAFHC cells. Final results represent mean \pm SD of three independent experiments. Statistical significance was evaluated by Student t-test $\left.{ }^{* *}, p<0.01,{ }^{* * * *}, p<0.0001\right)$. Western Blot analysis of FHC was performed on $50 \mu \mathrm{g}$ of total protein extract from

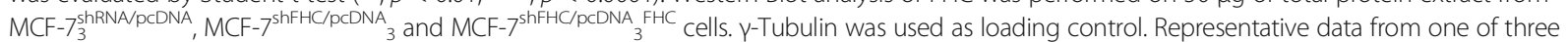
experiments. b Real-time PCR analysis of E-Cadherin, Vimentin, Twist and Slug were performed on total RNA extracted from MCF-7 shRNA

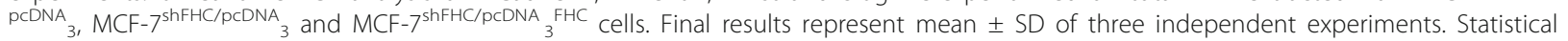
significance was evaluated by Student t-test $\left({ }^{*}, p<0.05,{ }^{*}, p<0.01,{ }^{* *}, p<0.001\right.$, n.S., not significant)

model, we treated MCF- $7^{\text {shFHC }}$ cells with the ROS scavenger $\mathrm{N}$-acetylcysteine (NAC), and analyzed the levels of the EMT markers. NAC treatment partially reversed the expression of Twist (about 25\%), Slug and Vimentin (about 40\%), while it left unaffected the amounts of Ecadherin (Panels B and C of Fig. 5). The addition of NAC to the culture medium of MCF- $7^{\text {shFHC }}$ cells did not substantially modify their migration capability (Panel D of Fig. 5), while, on the contrary, it significantly reduced their proliferation rate (Panel E of Fig. 5). Moreover, the spindleshaped morphology of the silenced cells remained substantially unaltered upon NAC addition (Panel F of Fig. 5).

\section{CXCR4 axis is constitutively activated in MCF-7 ${ }^{\text {shFHC }}$ cells} It has been shown that the binding of the chemokine CXCL12 to its CXCR4 receptor induces EMT in several cell types including MCF-7 cells [26-28, 44]. It has been also established that FHC binds the internalized CXCR4 receptor and impairs its transductional pathway [15] consisting, among others, in the inhibition of cAMP production and activation of ERK and AKT $[45,46]$. In the subsequent experiments we investigated whether CXCR4 is activated in MCF- $7^{\text {shFHC }}$ cells and to what extent this activation might play a role in the induction of the EMT phenotype. Upon FHC silencing, CXCR4 protein level increased of about two-fold, and the receptor was shifted towards the cell surface, even though not to a significant extent (Panels A and B of Fig. 6). In line with an activation of CXCR4 pathway in the silenced cells, the treatment with CXCL12 inhibited CAMP production more strongly in MCF- $7^{\text {shFHC }}$ cells than in the control ones. Moreover, this effect was only partially rescued by the canonical CXCR4 inhibitor AMD3100 (Panel C of Fig. 6). We also evaluated the CXCR4-mediated activation of ERK1/2 and PI3K/Akt; the levels of phospho-ERK (pERK) were mildly increased in MCF- $7^{\text {shFHC }}$ cells (Panel D of Fig. 6) and appeared substantially unaffected by treatment with CXCL12 and with AMD3100 (data not shown). Conversely, phospho-AKT 


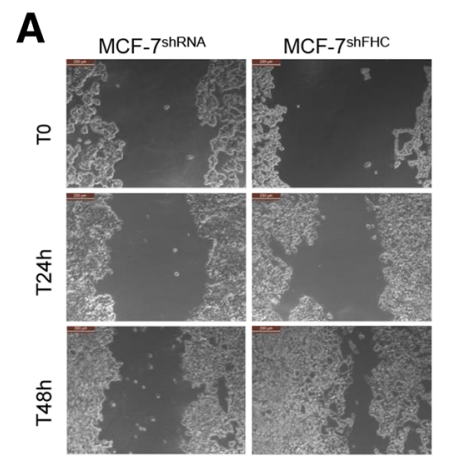

C
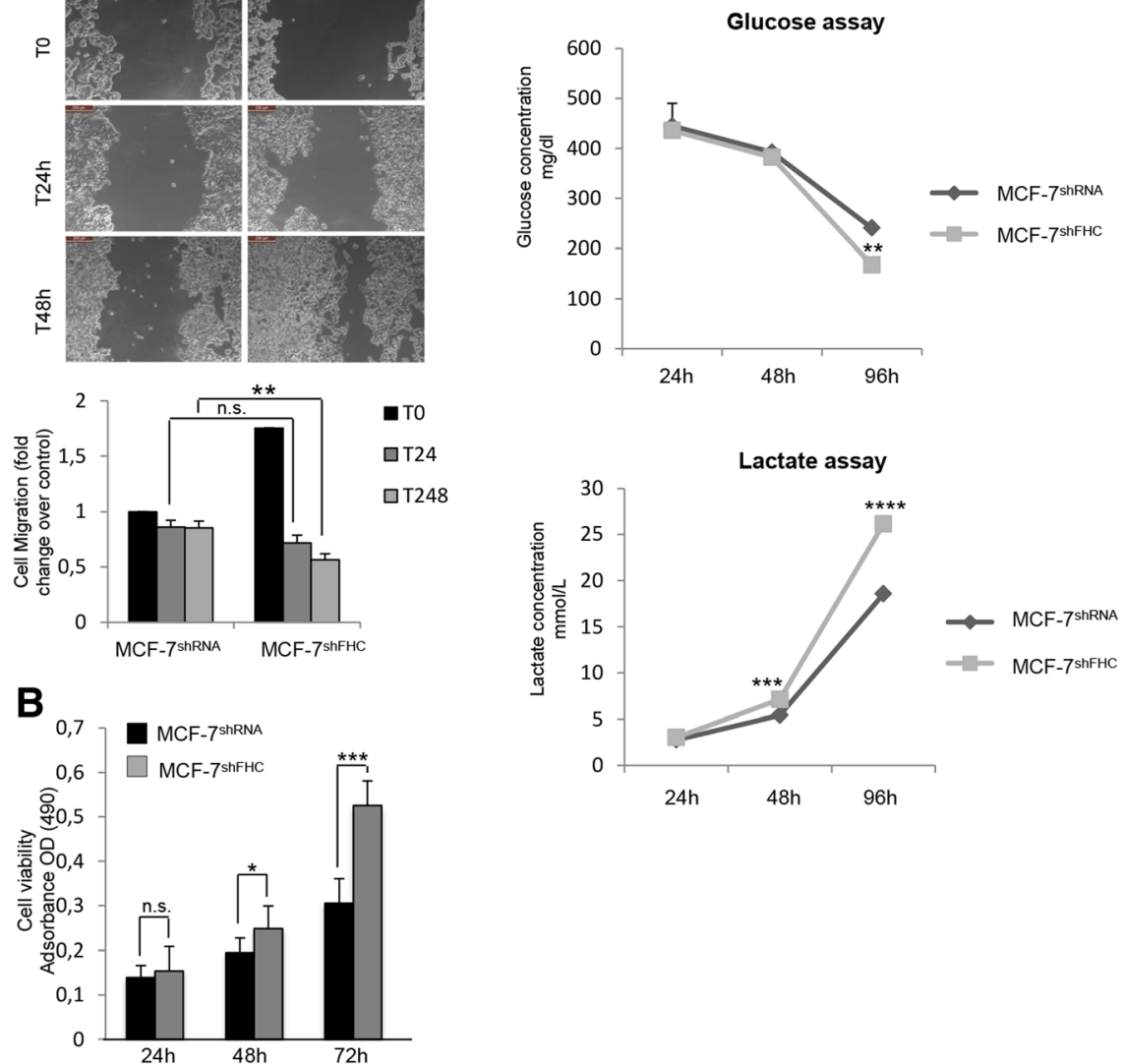

Fig. $4 \mathrm{MCF}-7^{\mathrm{shFHC}}$ cells shows a more aggressive phenotype. a Wound healing assay was conducted to measure migration capacity of MCF-7 $7^{\text {shRNA }}$ and MCF-7 $7^{\text {ShFHC }}$ cells. Images of cellular migration were taken at times $0 \mathrm{~h}, 24 \mathrm{~h}$ and $48 \mathrm{~h}$ (magnification of 10X) using the Leica DFC420 C and Leica Application Suite Software. Wound opening was quantified by ImageJ 64 software. Final results represent mean \pm SD of three independent experiments. Cell migration fold change was evaluated using the T0 of MCF-7 ${ }^{\text {shRNA }}$ as control. Statistical significance was evaluated by Two-Way ANOVA (Sidak's) (n.S. not significant, $\left.{ }^{* *}, p<0.01\right)$. b Cell viability was assessed in MCF-7 $7^{\text {shRNA }}$ and MCF- ${ }^{\text {shFHC }}$ cells using the MTT method, as indicated in the Methods section, at $24 \mathrm{~h}, 48 \mathrm{~h}$ and $72 \mathrm{~h}$. Final results represent mean \pm SD of three independent experiments. Statistical significance was evaluated by Two-Way ANOVA (Sidak's) (n.s. not significant, ${ }^{*}, p<0.01,{ }^{* *}, p<0.001$ ). c Cells were seeded in $10 \mathrm{ml}$ of DMEM in $100 \mathrm{~mm}$ plates. After $24 \mathrm{~h}, 48 \mathrm{~h}$ and $96 \mathrm{~h}, 500 \mu \mathrm{l}$ of supernatant were taken and glucose and lactate concentration was measured. Final results represent mean \pm SD of three independent experiments. Statistical significance was evaluated by Two-Way ANOVA (Sidak's) $\left(* *, p<0.01, * * *, p<0.001,{ }^{* * * *}, p<0.0001\right)$

(pAKT) was dramatically induced in MCF-7 $7^{\text {shFHC }}$ (lanes 1 and 5 of upper panel E of Fig. 6) and the addition of CXCL12 did not further increase pAKT activity (lanes 2 and 6 of the same panel). The lower western blot in panel $\mathrm{E}$ of Fig. 6 shows that the addition of AMD3100 is unable to rescue the pAKT induction detected in MCF- $7^{\text {shFHC }}$. Since CXCR4 has been shown to activate mTOR pathway via AKT [22] we also evaluated the levels of p-S6 ribosomal kinase (S6 K), the downstream effector of mTOR [47-49]. pAKT activation in MCF-7 ${ }^{\text {shFHC }}$ cells corresponded to increased phosphorylation of $\mathrm{S} 6 \mathrm{~K}$, which is not inhibited by AMD3100 (Fig. 6 Panel F). Thus, the significant increase of pAKT and its downstream target $\mathrm{S} 6 \mathrm{~K}$, suggests a strong activation of survival pathways through CXCR4 following ferritin silencing.
To further explore the impact of CXCL12/CXCR4 axis activation on phenotypic changes produced by ferritin heavy chain silencing, we measured migration and proliferation in the presence of CXCL12 in MCF- $7^{\text {shFHC }}$ versus MCF- ${ }^{\text {shRNA }}$ cells. CXCL12 induces an approximately 3-fold increase of migration capability both in MCF- $7^{\text {shRNA }}$ and MCF- $7^{\text {shFHC }}$ cells. Interestingly, when MCF- $7^{\text {shrNA }}$ and MCF-7 $7^{\text {shFHC }}$ cells were exposed to AMD3100 a decrease in migration was detected (Panel $\mathrm{G}$ of Fig. 6). With regard to cell growth, the presence of CXCL12 in the culture medium did not produce any proliferative advantage in MCF- $7^{\text {shFHC }}$ vs. MCF- $7^{\text {shRNA }}$ and AMD3100 inhibited growth rate to the same extent both in FHC-silenced and unsilenced cells (data not shown). 


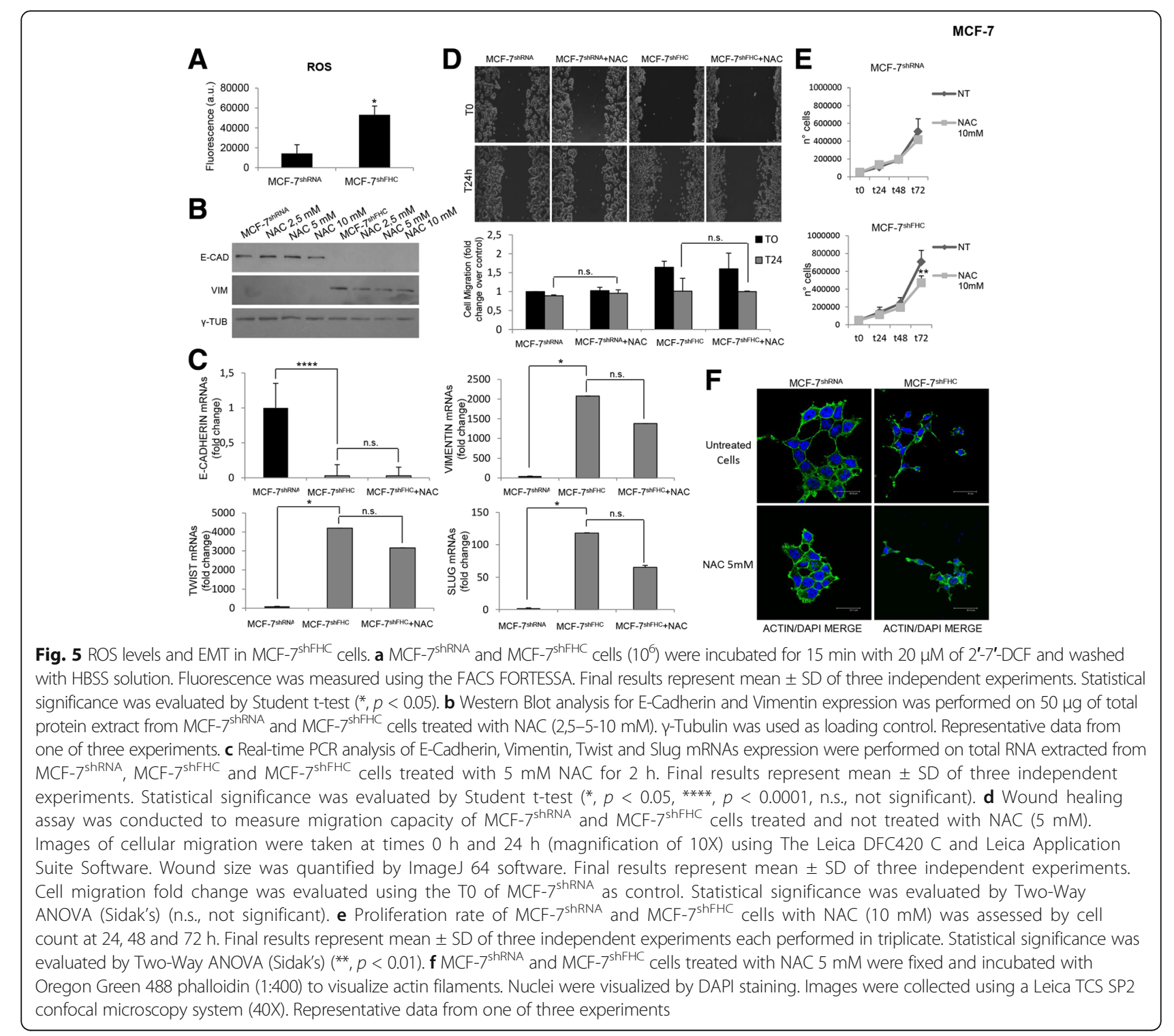

\section{FHC silencing induces EMT and a more aggressive phenotype in $\mathrm{H} 460$ cells}

To verify if the role of FHC silencing in EMT is restricted to MCF-7 cells or if it represents a more general phenomenon, we reproduced most of the analysis in the lung tumor NCI-H460 (H460) cells either FHC-silenced $\left(\mathrm{H} 460^{\text {shFHC }}\right)$ or unsilenced $\left(\mathrm{H} 460^{\text {shRNA }}\right)$ cells (Panel A of Fig.7). The reason for this choice lies in the fact that we recently published that FHC silencing of $\mathrm{H} 460$ cells determines increased ROS production, enhanced cell viability and activation of AKT [13]. Moreover, the analysis of glucose/lactate metabolism, shown in Panel B of Fig. 7, suggests a more aggressive phenotype of $\mathrm{H} 460^{\text {shFHC }}$ compared to $\mathrm{H} 460^{\text {shRNA }}$ cells. Consequently we evaluated the EMT markers by western blot and qPCR analysis. The results are shown in Panel $\mathrm{C}$ of Fig. 7.

As in MCF-7 cells, also in the $\mathrm{H} 460$ cells FHC knockdown is accompanied by a reduced expression of Ecadherin and by an up-regulation of Vimentin, Twist, Slug and ZEB1. Moreover, consistently with the acquisition of EMT properties, $\mathrm{H} 460^{\text {shFHC }}$ cells gained greater migratory capacity than control cells at $48 \mathrm{~h}$ (Panel D of Fig. 7). The expression levels of these molecules were partially restored upon NAC treatment. Panel A of Fig. 8 shows that Twist levels are reduced of about $50 \%$ and that Slug and Vimentin are reduced of about $45 \%$ in the NAC-treated $\mathrm{H} 460^{\text {shFHC }}$ compared to the untreated $\mathrm{H} 460^{\text {shFHC }}$. Unlike MCF-7 cells, ROS chelation was able to partially restore E-cadherin expression. ROS chelation 


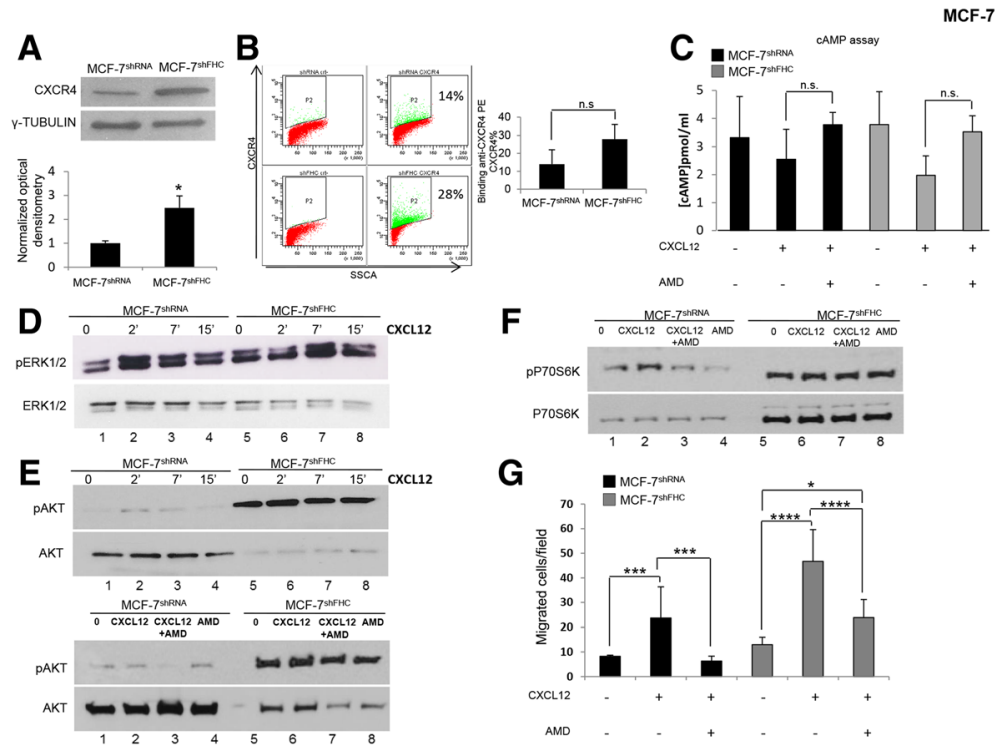

Fig. 6 CXCR4 axis is activated in MCF-7 $7^{\text {shFHC }}$ cells. a Western Blot analysis for CXCR4 expression was performed on $50 \mu$ of total protein extract from

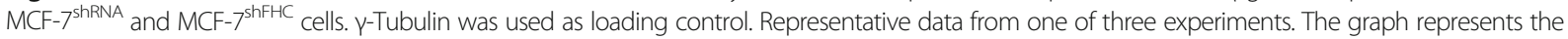
mean of the optical densities. Statistical significance was evaluated by Student t-test $\left(^{*}, p<0.05\right)$. b Cells were stained with anti-CXCR4 PE $\left(10 \mu \mathrm{L} / 1 \times 10^{6}\right.$ cells) and evaluated by a FACS Canto II cytofluorometer. Final results represent mean \pm SD of three independent experiments. Statistical significance was evaluated by Student t-test (n.S., not significant). c cAMP production was verified after Forskolin (1 $\mu \mathrm{M})$, CXCL12 (100 ng/mL), and AMD3100 $(10 \mu M)$ treatment in MCF7 cells. Final results represent mean \pm SD of three independent experiments. Statistical significance was evaluated by Two-Way ANOVA (Tukey's) (n.S., not significant). d Western Blot analysis for pERK1/2 was performed on $50 \mu \mathrm{g}$ of total

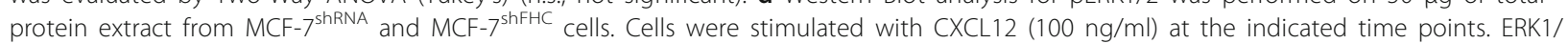
2 was used as loading control. Representative data from one of three experiments. Numbers below the western blot indicates sample progression. e Upper: Western Blot analysis for pAKT was performed on $50 \mu \mathrm{g}$ of total protein extract from MCF- $7^{\text {shRNA }}$ and MCF-7 ${ }^{\text {shFHC }}$ cells. Cells were stimulated with CXCL12 $(100 \mathrm{ng} / \mathrm{ml})$ at the indicated time points. AKT was used as loading control. Numbers below the western blot indicates sample progression. Lower: Cells were stimulated with CXCL12 (100 ng/ml for 10 min) and treated with the AMD3100 $(10 \mu \mathrm{M})$ one hour before their exposure to CXCL12. AKT was used as loading control. Numbers below the western blot indicates sample progression. Representative data from one of three experiments. $\mathbf{f}$ Western Blot analysis for pP70S6 K expression was performed on $50 \mu \mathrm{g}$ of total protein extract from MCF- $7^{\text {shRNA }}$ and MCF-7 $7^{\text {shFHC }}$ cells. Cells were stimulated with CXCL12 (100 ng/ml for $\left.10 \mathrm{~min}\right)$ and treated with the AMD3100 (10 $\mu$ M) one hour before their exposure to CXCL12. P70S6 K was used as loading control. Numbers below the western blot indicates sample progression. Representative data from one of three experiments. $\mathbf{g}$ CXCL12 dependent-cell migration was examined in 24-well plates. Cells were placed in the upper chamber ( $8 \mu \mathrm{m})$ in the presence of AMD3100 $(10 \mu \mathrm{M})$. Cells migrated toward CXCL12 $(100 \mathrm{ng} / \mathrm{ml})$ for $18 \mathrm{~h}$. The cells were counted in ten different consecutive high power fields (magnification 200X). Final results represent mean \pm SD of three independent experiments. Statistical significance was evaluated by Two-Way ANOVA (Tukey's) $\left(^{*}, p<0.05,{ }^{* * *}, p<0.001,{ }^{* * *}, P<0.0001\right)$.

also reduced the enhanced proliferative rate of $\mathrm{H} 460^{\text {shFHC }}$ cells, as shown in Panel B of Fig. 8.

As demonstrated in MCF-7 cells, FHC-silencing deregulated CXCR4 expression also in H460 cells. The steady-state amount of the receptor, evaluated by western blot, was about doubled in $\mathrm{H} 460^{\text {shFHC }}$ cells with an increased localization, even though not statistically significant on the cell surface (Fig. 9, Panel a and Panel b). Along with the activation of AKT, which has been already demonstrated [13], FHC knock-down increased pERK expression, as shown in Panel $\mathrm{C}$ of Fig. 9. $\mathrm{H} 460^{\text {shFHC }}$ cells were also treated with CXCL12 and with AMD3100 and pERK and pAKT levels were evaluated. The results, shown in Panel $\mathrm{C}$ of Fig. 9, are similar to those obtained with MCF$7^{\text {shFHC }}$ cells, since the levels of the two kinases were unaffected by treatment with CXCL12 and AMD3100.
Finally, we analyzed the migration of $\mathrm{H} 460$ cells in the presence of AMD3100 demonstrating that the CXCR4 inhibitor consistently reduced the migratory capability of the H460 ${ }^{\text {shFHC }}$ cells treated with CXCL12 (Panel D of Fig. 9).

Taken all together these results indicate that, albeit less dramatically than in MCF-7 cells, FHC silencing induces EMT and enhanced aggressiveness also in the lung tumor $\mathrm{H} 460$ cells and that these phenomena are attributable to both ROS increase and CXCR4 activation.

\section{Discussion}

In the last years we and others have highlighted the role of ferritin heavy chain in the process of neoplastic transformation. We have documented that the modulation of FHC content determines, in different cell types, a severe alteration of gene expression, as evaluated by proteomic [29] and transcriptomic analysis [34]. In 
A
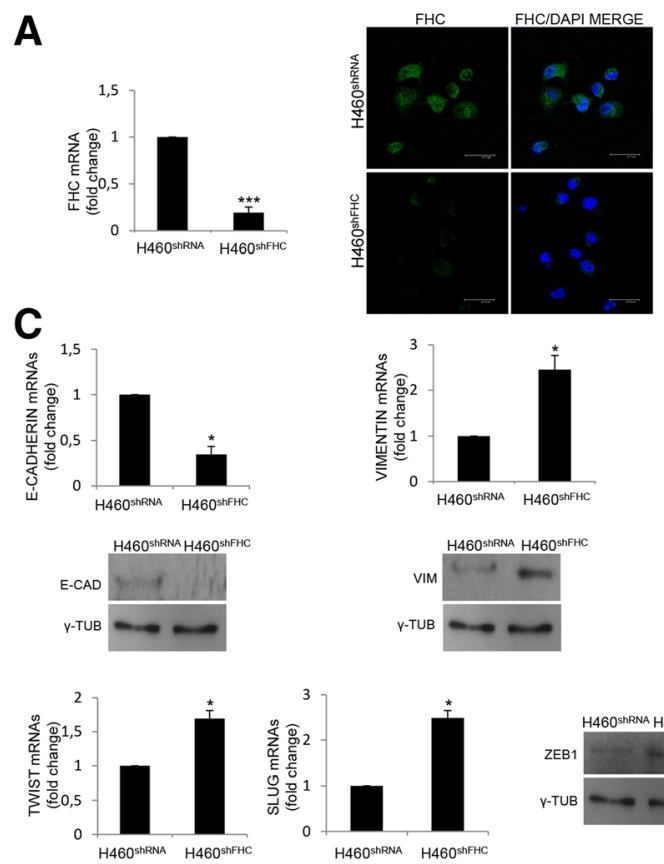
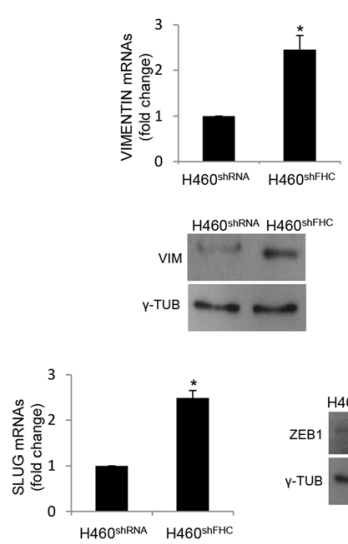

B
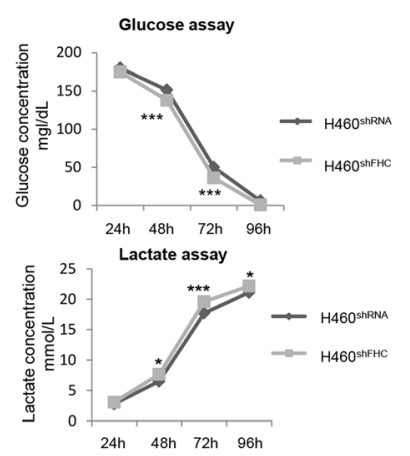

D

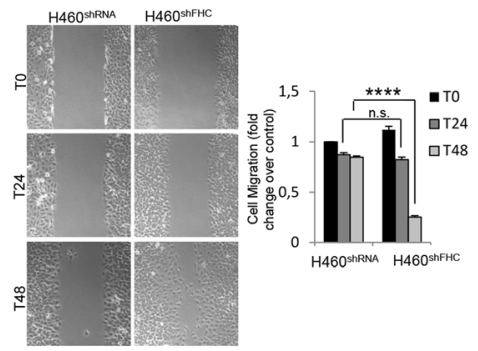

Fig. 7 FHC silencing induces EMT in H460 cells. a Real-time PCR analysis of FHC mRNAs expression were performed on total RNA extracted from $\mathrm{H}_{460} \mathrm{ShRNA}^{\text {ha }} \mathrm{H} 460^{\text {shFHC }}$ cells. Final results represent mean \pm SD of three independent experiments. Statistical significance was evaluated by Student

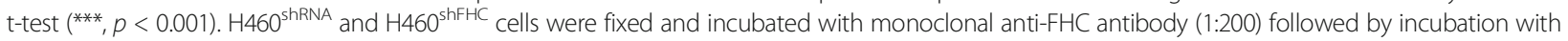
the appropriate secondary antibody. Nuclei were visualized by DAPI staining. Images were collected using a Leica TCS SP2 confocal microscopy system (63x). Representative data from one of three experiments. b Cells were seeded in $10 \mathrm{ml}$ of RPMl in $100 \mathrm{~mm}$ plates. After $24 \mathrm{~h}, 48 \mathrm{~h}, 72 \mathrm{~h}$ and $96 \mathrm{~h}$, $500 \mu \mathrm{l}$ of supernatant were taken and glucose and lactate concentration was measured. Final results represent mean \pm SD of three independent experiments. Statistical significance was evaluated by Two-Way ANOVA (Sidak's) $\left(^{*}, p<0.05,{ }^{* * *}, p<0.001\right)$. c Real-time PCR analysis of E-Cadherin, Vimentin, Twist and Slug. mRNAs expression was performed on total RNA extracted from H460 shRNA and H460 shFHC cells. Final results represent mean \pm SD of three independent experiments. Statistical significance was evaluated by Student t-test $\left({ }^{*}, p<0.05\right)$. Western Blot analysis for Vimentin, ZEB1 and E-Cadherin were performed on $100 \mu \mathrm{g}$ of total protein extract from $\mathrm{H}_{460} \mathrm{shRNA}^{\mathrm{s}} \mathrm{and} \mathrm{H} 460^{\text {shFHC }}$

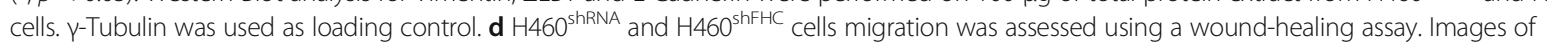
wounded monolayer of H460 cells were taken at times 0 h, 24 h and 48 h (magnification of 10X) using the Leica DFC420 C and Leica Application Suite Software. Wound size was quantified by ImageJ 64 software. Final results represent mean \pm SD of three independent experiments. Cell migration fold change was evaluated using the TO of $\mathrm{H}_{460^{\text {shRNA }}}$ as control. Statistical significance was evaluated by Two-Way ANOVA (Sidak's) (n.S., not significant ${ }^{* * *}, p<0.0001$ )

human metastatic melanoma cells this phenomenon is accompanied by a reduced invasiveness and adhesion along with a strong decrease in growth activity [29]. On the contrary, in two epithelium-derived cell lines, namely the human lung cancer cells H460 and the ovarian cancer cells SKOV3, FHC-silencing induced an increase of cell proliferation rate $[13,19]$. In addition, in SKOV3 cells FHC knock-down led to the acquisition of stemness properties along with a strong EMT phenotype [19]. Other groups have highlighted the role of FHC in neoplastic cells, underlining, for example, its ability to modulate the activity of p53 and DAXX [14, 50]. The molecular basis of this phenomenon is still under investigation and conflicting results have been obtained. Zhang et al. demonstrated that the acquisition of EMT phenotype in AML-12 murine hepatocytes and in human A459 lung cancer cells is due to increased ROS production induced by $\mathrm{FHC}$ down-regulation [10]. In
SKOV3 cells we correlated the EMT and the more aggressive phenotype of FHC-silenced cells to the altered expression of miR-125b, miR-146a and miR-150 [19].

Here, we studied the role of FHC in MCF-7 human breast cancer cells and in H460 lung cancer cells, demonstrating that silencing of ferritin heavy subunit increases cell aggressiveness through induction of EMT, increased proliferation rate and migratory ability. The major finding of this work is that FHC knock-down is accompanied, along with increased ROS production, by a strong activation of the CXCR4 transductional pathway, and that both these phenomena are responsible for the enhanced tumorigenic phenotype. In both MCF-7 and H460 cells, indeed, the treatment of the FHC-lacking cells with the ROS inhibitor NAC does not fully rescue the EMT phenotype while significantly affects the proliferation rate of silenced cells. On the contrary, MCF- $7^{\text {shFHC }}$ and 

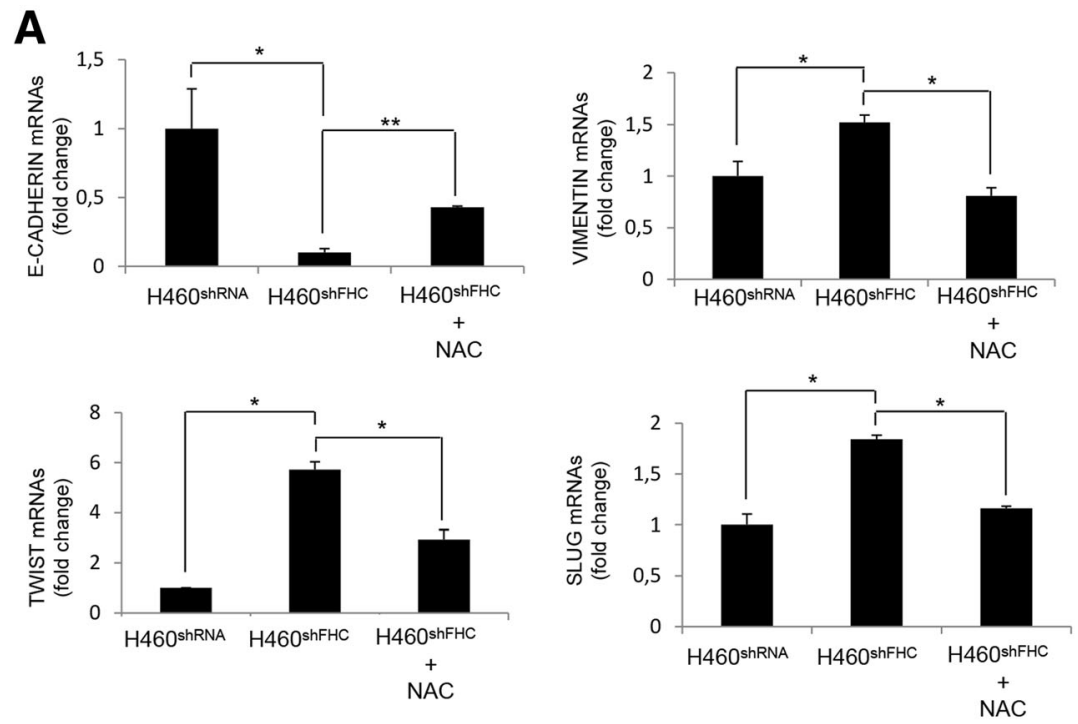

B
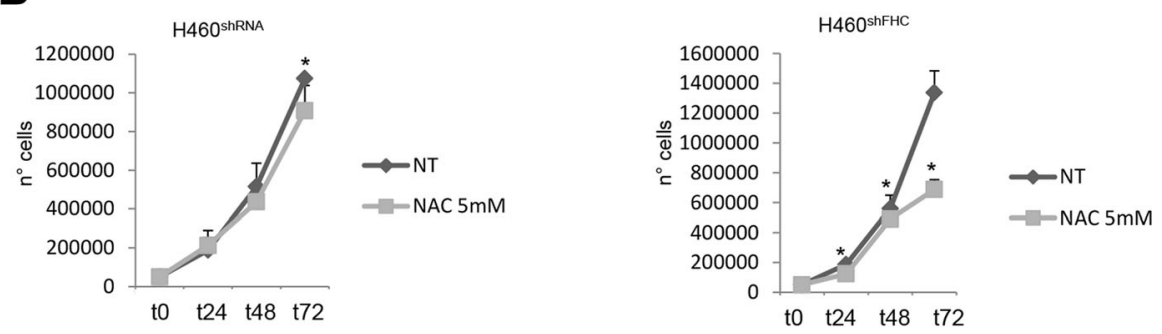

Fig. 8 NAC treatment affects EMT markers expression and cell proliferation in H460 cells (a). Real-time PCR analysis of E-Cadherin, Vimentin, Twist and Slug mRNAs expression were performed on total RNA extracted from H460 ${ }^{\text {shRNA }}, H 460^{\text {shFHC }}$ and H460 ${ }^{\text {shFHC }}$ cells treated with 5 mM NAC for 2 h. Final results represent mean \pm SD of three independent experiments. Statistical significance was evaluated by Student t-test $\left(^{*}, p<0.05,{ }^{* *}, p<0.01\right)$. $\mathbf{b}$ Proliferation rate of $\mathrm{H} 460^{\text {shRNA }}$ and $\mathrm{H} 460^{\text {shFHC }}$ cells with NAC $(10 \mathrm{mM})$ was assessed by cell count at 24,48 and $72 \mathrm{~h}$. Final results represent mean $\pm \mathrm{SD}$ of three independent experiments each performed in triplicate. Statistical significance was evaluated by Two-Way ANOVA (Sidak's) $\left(^{*}, p<0.05\right)$

$\mathrm{H} 460^{\text {shFHC }}$ cells show a strong reduction of their migratory capability when exposed to the CXCR4 inhibitor AMD3100.

These results are in line with the actual concept that FHC is a multifunctional molecule involved, from one hand, in intracellular iron homeostasis, and from the other in pathways not directly related to iron metabolism, such as the inhibition of cell death [13, 51, 52]. Among the non-iron related functions, FHC is able to interfere with CXCR4 signalling. Previous evidences have shown that FHC binds and inhibits CXCR4 function in HEK293 and in HeLa cells; the CXCR4-mediated ERK1/ 2 activation and chemotaxis are strongly inhibited by FHC-overexpression and, conversely, prolonged by FHC down-regulation [15]. Moreover, the binding of FHC to CXCR4 induces FHC phosphorylation at serine 178 and nuclear translocation [15]. The functional outcomes of CXCR4/FHC interaction have been widely investigated in neurons, in both physiological and pathological conditions [53-55]. In these cells, the long-term treatment with $\mathrm{Mu}$ opioid receptor (MOR) agonists, such as morphine, inhibits CXCL12-induced activation of CXCR4 and the related downstream signalling through ERK and AKT [56]. The opiate-induced inhibition of CXCR4 requires de novo protein synthesis and up-regulation of FHC that acts as negative modulator of CXCR4 [15]. The neuronal levels of FHC are augmented by MOR stimulation both in vitro (i.e. neuronal cultures) and in vivo (i.e. rat brain), always leading to CXCR4 impairment [56].

Our data indicate that in MCF-7 and H460 cells FHC knock-down increases CXCR4 surface expression and signalling, and that the activation of this pathway is largely responsible for the increase in migration capability. The analysis of the CXCR4 downstream patterns shows a consistent analogy with the reported role of FHC in neurons, since also in MCF-7 and H460 cells FHC down-regulation is accompanied by activation of ERK and AKT. Interestingly, pERK and pAKT amounts 


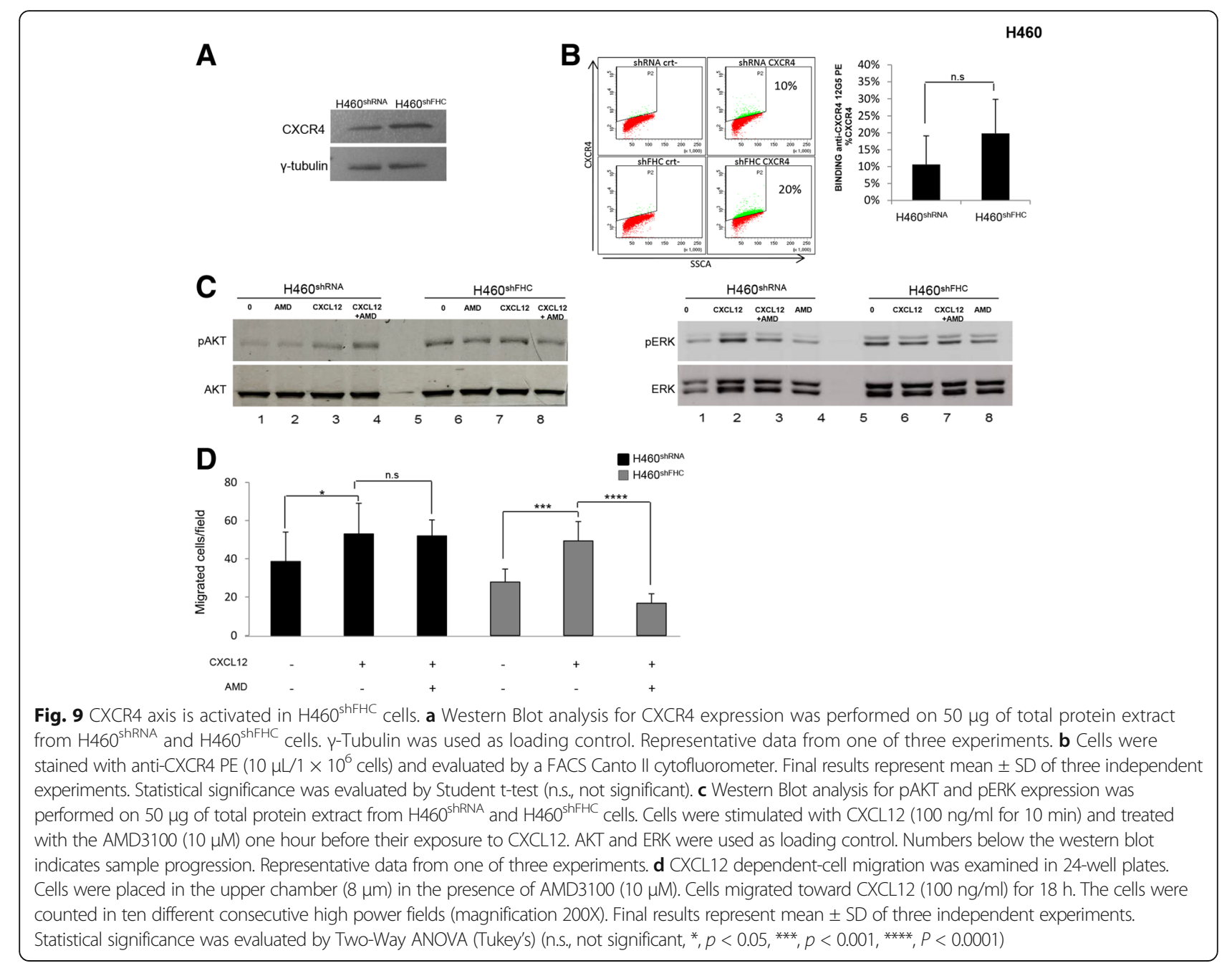

in silenced cells are not further modified by CXCL12 treatment or by the use of the CXCR4 inhibitor AMD3100, while the inhibition of cAMP production is responsive to the cytokine as well as to the inhibitor. The unresponsiveness of pAKT to CXCL12 and AMD3100 is likely due to the fact that the silencing of ferritin induces a constitutive active CXCR4 transduction pathway, which is poorly affected by the two treatments. Overall, these data suggest that, among the downstream targets of CXCR4, FHC insists particularly on the signalling mediated by MAP Kinases and PI3KpAKT pathways. Moreover, the increase in pAKT expression levels in MCF-7 ${ }^{\text {shFHC }}$ cells corresponds to S6 K induction suggesting an activation of the AKT-mTORrelated survival pathway, as previously reported downstream of CXCR4 in neurons and renal cell lines [22].

CXCR4 and its downstream pathways have been widely investigated in cancer and EMT. Among others, Roccaro et al. [55] demonstrated that CXCR4 enhances the acquisition of an EMT-like phenotype in multiple myeloma (MM) cells with a phenotypic conversion towards invasion, leading to higher bone metastasis and extramedullary disease dissemination in vivo. In contrast, CXCR4 silencing leads to inhibition of tumor growth and to reduced survival. Grundker et al. [44] showed that CXCL12 induces invasion and EMT genes in MCF-7 and T-47-D breast cancer cells. Less is known about the interference of FHC on CXCR4 signalling in neoplastic cells; to our knowledge this is one of the first reports on the CXCR4-mediated FHC role in cancer.

The differences between our findings in MCF-7 and H460 cells and those of Zhang et al. in AML-12 and A459 cells deserve a further consideration. In AML-12 cells, in fact, EMT is exclusively promoted by ROS increase, which, in turn, is induced by FHC downregulation. NAC treatment completely reversed EMT phenotype and strongly affected proliferation and migration indexes. We hypothesize that the different behaviour of FHC-silencing might be attributed to a different cell-specific activity of the ferritin heavy subunit. In the 
context of the emerging multiple functions played by this molecule, it is reasonable to postulate that FHC acts as house-keeping protein for the functions related to iron/redox metabolism, while its role in other metabolisms is strictly dependent on the cell type.

\section{Conclusions}

Despite the large number of studies on ferritin and particularly on its heavy subunit in neoplastic cells, the role of FHC in CXCR4 signalling in cancer has not been addressed so far. The activation of CXCL12/CXCR4 axis enhances migration and invasion of cancer cells, thus leading to metastasis $[57,58]$ and may regulate antitumor immune response through T cells access [59]. Thus, the integrity of FHC-regulated pathways may be a tool to predict tumor aggressiveness. Increased EMT, migration and survival depend on release of FHC control on several pathways such as ROS and CXCR4; therefore, targeting FHC-ROS-CXCR4 axis could reverse these effects. Further studies are needed to define in details the molecular effects of FHC/CXCR4 interaction; nevertheless, we believe that our findings might have relevant implications in the design of new therapeutic approaches.

\section{Abbreviations}

BSA: Bovine serum albumin; CNS: Central nervous system; CXCL12: C-X-C motif chemokine ligand 12; CXCR4: C-X-C chemokine receptor type 4; DMEM: (Dulbecco's Modified Eagle Medium; ECL: Electrochemiluminescence; EMT: Epithelial to mesenchymal transition; FBS: Fetal bovine serum; FHC: Heavy chain of ferritin; FTH or FHC: Ferritin heavy chain; FTL: Ferritin light chain; GAPDH: Glyceraldehyde 3-phosphate dehydrogenase; GPCR: G protein-coupled receptor; HEK-293 T: Human embryonic kidney cells 293; HS: High salt solution; LIP: Labile Iron Pool; MOR: Mu opioid receptor; MTT: 3-(4,5-dimethylthiazol-2-yl)-2, 5-diphenyl tetrazolium bromide; NAC: N-acetylcysteine; O.D: Opticla Density; PBS: Phosphate buffered saline; PFA: Paraformaldehyde; qRT-PCR: Quantitative RT-PCR; ROS: reactive species of oxygen; RPMI: Roswell Park Memorial Institute medium; SDS: Sodium dodecyl sulfate; shRNA: Short hairpin; TPBS: Tris buffered saline
\end{abstract}

\section{Acknowledgements}

We thank Caterina Alessi for editorial assistance.

\section{Funding}

This work was supported in part by the MIUR grant PON03PE_00009_2 (iCARE) to GC.

\section{Availability of data and materials}

The datasets used and/or analysed during the current study available from the corresponding author on reasonable request.

\footnotetext{
Authors' contributions

$\mathrm{Al}$ and $\mathrm{ZF}$ carried out most of the experiments, IC and TAM carried out experiments relative to CXCR4/CXCL12 axis, BS performed analysis of confocal microscopy, FMC performed FHC silencing and contributed to the materials and methods section of the manuscript, DC, MD and BF revised the final version of the manuscript, VG suggested some experiments and revised the final version of the manuscript, SS planned and supervised the experiments relative to CXCR4/CXCL12 axis, wrote large sections of the manuscript, CG wrote large sections of the manuscript and revised the final version, CF conceived the initial silencing study of FHC in MCF-7 and NCl-H460 cells, supervised most of the experiments and wrote large sections of the manuscript. All authors read and approved the final manuscript.
}

Ethics approval and consent to participate

Not applicable.

\section{Consent for publication}

Not applicable.

Competing interests

The authors declare that they have no competing interests.

\section{Publisher's Note}

Springer Nature remains neutral with regard to jurisdictional claims in published maps and institutional affiliations.

\section{Author details}

${ }^{1}$ Research Center of Advanced Biochemistry and Molecular Biology, Department of Experimental and Clinical Medicine, Magna Græcia University of Catanzaro, Salvatore Venuta Campus, Viale Europa, 88100 Catanzaro, Italy. ${ }^{2}$ Genomica Funzionale, INT Pascale, Napoli, Italy. ${ }^{3}$ Department of Health Sciences, Magna Græcia University of Catanzaro, Salvatore Venuta Campus, Viale Europa, 88100 Catanzaro, Italy. ${ }^{4}$ Department of Experimental and Clinical Medicine University of Catanzaro "Magna Graecia", 88100 Catanzaro, Italy.

Received: 6 June 2017 Accepted: 24 July 2017

Published online: 03 August 2017

\section{References}

1. Savagner P. Leaving the neighborhood: molecular mechanisms involved during epithelial-mesenchymal transition. BioEssays. 2001;23:912-23.

2. Mani SA, Guo W, Liao MJ, Eaton EN, Ayyanan A, Zhou AY. The epithelialmesenchymal transition generates cells with properties of stem cells. Cell. 2008:133:704-15.

3. Barrallo-Gimeno A, Nieto MA. The snail genes as inducers of cell movement and survival: implications in development and cancer. Development. 2005; 132:3151-61.

4. Derksen PW, Liu X, Saridin F, van der Gulden H, Zevenhoven J, Evers B, et al. Somatic inactivation of E-cadherin and p53 in mice leads to metastatic lobular mammary carcinoma through induction of anoikis resistance and angiogenesis. Cancer Cell. 2006;10:437-49.

5. Thiery J, Acloque H, Huang RY, Nieto MA. Epithelial-mesenchymal transitions in development and disease. Cell. 2009;139:871-90.

6. Go J. Yoshida emerging role of epithelial-mesenchymal transition in hepatic cancer. J Exp Clin Cancer Res. 2016:35(1):141.

7. Zhang Y, Zeng S, Ma J, Deng G, Qu Y, Guo C, et al. Nestin overexpression in hepatocellular carcinoma associates with epithelial-mesenchymal transition and chemoresistance. J Exp Clin Cancer Res. 2016;35:111.

8. Xu J, Liu D, Niu H, Zhu G, Xu Y, Ye D, et al. Resveratrol reverses doxorubicin resistance by inhibiting epithelial-mesenchymal transition (EMT) through modulating PTEN/Akt signaling pathway in gastric cancer. J Exp Clin Cancer Res. 2017;36:19.

9. Barriga EH, Maxwell PH, Reyes AE, Mayor R. The hypoxia factor Hif-1a controls neural crest chemotaxis and epithelial to mesenchymal transition. J Cell Biol. 2013;201(5):759-76.

10. Zhang KH, Tian HY, Gao X, Lei WW, Hu Y, Wang DM, et al. Ferritin heavy chain-mediated iron homeostasis and subsequent increased reactive oxygen species production are essential for epithelial-mesenchymal transition. Cancer Res. 2009;69(13):5340-8.

11. Orino K, Watanabe K. Molecular, physiological and clinical aspects of the iron storage protein ferritin. Vet J. 2008;178:191-01.

12. Crichton RR, Declercq JP. X-ray structures of ferritins and related proteins. Biochim Biophys Acta. 2010;1800:706-18.

13. Zolea F, Biamonte F, Battaglia AM, Faniello MC, Cuda G, Costanzo F. Caffeine positively modulates Ferritin heavy chain expression in $\mathrm{H} 460$ cells: effects on Cell proliferation.. PLoS One 2016; 11(9):e0163078.

14. Lee $\mathrm{JH}$, Jang $\mathrm{H}$, Cho EJ, Youn HD. Ferritin binds and activates p53 under oxidative stress. Biochem Biophys Res Commun. 2009;389(3):399-04.

15. Li R, Luo C, Mines M, Zhang J, Fan GH. Chemokine CXCL12 induces binding of Ferritin heavy chain to the Chemokine receptor CXCR4, alters CXCR4 signaling, and induces Phosphorylation and nuclear translocation of Ferritin heavy chain. J Biol Chem. 2006;281(49):37616-27. 
16. Coffman LG, Parsonage D, D'Agostino RJ, Torti FM, Torti SV. Regulatory effects offerritinon angiogenesis. Proc Natl Acad Sci U S A. 2009;106(2):570-5.

17. Biamonte F, Zolea F, Bisognin A, Di Sanzo M, Saccoman C, Scumaci D, et al. $\mathrm{H}$-Ferritin-regulated MicroRNAs modulate gene expression in K562 cells. PLoS One. 2015;10(3):e0122105.

18. Zolea F, Biamonte F, Candeloro P, Di Sanzo M, Cozzi A, Di Vito A, et al. H ferritin silencing induces protein misfolding in K562 cells: a Raman analysis. Free RadicBiolMed. 2015;89:614-23.

19. Lobello N, Biamonte F, Pisanu ME, Faniello MC, Jakopin Z, Chiarella E, et al. Ferritin heavy chain is a negative regulator of ovarian cancer stem cell expansion and epithelial to mesenchymal transition. Oncotarget. 2016;7:62019-33.

20. Scala S. Molecular pathways: targeting the CXCR4-CXCL12 Axis-untapped potential in the tumor leukemia. Clin Cancer Res. 2016;21(19):4278-85.

21. Zou YR, Kottmann AH, Kuroda M, Taniuchi I, Littman DR. Function of the chemokine receptor CXCR4 in haematopoiesis and in cerebellar development. Nature. 1998;393(6685):595-9.

22. leranò C, Santagata S, Napolitano M, Guardia F, Grimaldi A, Antignani E, et al. CXCR4 and CXCR7 transduce through mTOR in human renal cancer cells. Cell Death Dis. 2014;5:e1310.

23. Burger JA1, Kipps TJ. CXCR4: a key receptor in the crosstalk between tumor cells and their microenvironment. Blood. 2006;107:1761-7.

24. Zhao S1, Wang J2, Qin C3. Blockade of CXCL12/CXCR4 signaling inhibits intrahepatic cholangiocarcinoma progression and metastasis via inactivation of canonical Wnt pathway. J Exp Clin Cancer Res. 2014;33:103.

25. D'Alterio C1, Barbieri A, Portella L, Palma G, Polimeno M, Riccio A, et al. Inhibition of stromal CXCR4 impairs development of lung metastases. Cancer Immunol Immunother. 2012;61(10):1713-20.

26. Hu TH, Yao Y, Yu S, Han LL, Wang WJ, Guo H, et al. SDF-1/CXCR4 promotes epithelial-mesenchymal transition and progression of colorectal cancer by activation of the Wnt/ß-catenin signaling pathway. Cancer Lett. 2014;354:417-26.

27. Li X, Li P, Chang Y, Xu Q, Wu Z, Ma Q. The SDF-1/CXCR4 axis induces epithelial-mesenchymal transition in hepatocellular carcinoma. Mol Cell Biochem. 2014;392:77-84

28. Mercurio L, Ajmone-Cat MA, Cecchetti S, Ricci A, Bozzuto G, Molinari A, et al. Targeting CXCR4 by a selective peptide antagonist modulates tumor microenvironment and microglia reactivity in a human glioblastoma model. J Exp Clin Cancer Res. 2016;35:55.

29. Di Sanzo M, Gaspari M, Misaggi R, Romeo F, Falbo L, De Marco C. H ferritin gene silencing in a human metastatic melanoma cell line: a proteomic analysis. J Proteome Res. 2011:10(12):5444-53.

30. Roperto S, Borzacchiello G, Brun R, Costanzo F, Faniello MC, Raso C, et al. Ferritin heavy chain $(\mathrm{FHC})$ is up-regulated in papillomavirus-associated urothelial tumours of the urinary bladder in cattle. J Comp Pathol. 2010;142(1):9-18.

31. Faniello MC, Di Sanzo M, Quaresima B, Nisticò A, Fregola A, Grosso M, et al. Bilateral cataract in a subject carrying a $C$ to a transition in the $L$ ferritin promoter region. Clin Biochem. 2009;42(9):911-4.

32. Qin L, Jia P, Zhang Z, Zhang S. ROS-p53-cyclophilin-D signaling mediates salinomycin-induced glioma cell necrosis. J Exp Clin Cancer Res. 2015;34:57.

33. Chen X, Guan X, Zhang H, Xie X, Wang H, Long J, et al. DAL-1 attenuates epithelialto mesenchymal transition in lung cancer. J Exp Clin Cancer Res. 2015;34:3.

34. Misaggi R, Di Sanzo M, Cosentino C, Bond HM, Scumaci D, Romeo F, et al. Identification of $\mathrm{H}$ ferritin-dependent and independent genes in $\mathrm{K} 562$ differentiating cells by targeted gene silencing and expression profiling. Gene. 2014;535(2):327-35.

35. Ji X, Woodard AS, Rimm DL, Fearon ER. Transcriptional defects underlie loss of E-cadherin expression in breast cancer. Cell Growth Differ. 1997;8:773-8.

36. Ke Z, Zhou F, Wang L, Chen S, Liu F, Fan X, Tang F, Liu D, Zhao G. Downregulation of Wnt signaling could promote bone marrow-derived mesenchymal stem cells to differentiate into hepatocytes. Biochem Biophys Res Commun. 2008;367(2):342-8. doi:10.1016/j.bbrc.2007.12.134

37. Kaufhold S, Bonavida B. Central role of Snail1 in the regulation of EMT and resistance in cancer: a target for therapeutic intervention. J Exp Clin Cancer Res. 2014;33:62.

38. Sun X, Cui M, Zhang A, Tong L, Wang K, Li K, et al. MiR-548c impairs migration and invasion of endometrial and ovarian cancer cells via downregulation of twist. J Exp Clin Cancer Res. 2016:35:10.

39. Lv X, Li L, Lv L, Qu X, Jin S, Li K, et al. HOXD9 promotes epithelial-mesenchymal transition and cancer metastasis by ZEB1 regulation in hepatocellular carcinoma. J Exp Clin Cancer Res. 2015;34:133.

40. Kakhlon O, Cabantchik ZI. The labile iron pool: characterization, measurement, and participation in cellular processes. Free Radic Biol Med. 2002;33:1037-46.
41. Omiya S, Hikoso S, Imanishi Y, Saito A, Yamaguchi O, Takeda T, et al Downregulation of ferritin heavy chain increases labile iron pool, oxidative stress and cell death in cardiomyocytes. J Mol Cell Cardiol. 2009;46(1):59-66.

42. Hu Y, He K, Wang D, Yuan X, Liu Y, Ji H, et al. TMEPAl regulates EMT in lung cancer cells by modulating the ROS and IRS-1 signaling pathways. Carcinogenesis. 2013;34(8):1764-72

43. Udensi UK, Tchounwou PB. Oxidative stress in prostate hyperplasia and carcinogenesis. J Exp Clin Cancer Res. 2016;35(1):139.

44. Gründker C, Bauerschmitz G, Knapp J, Schmidt E, Olbrich T, Emons G. Inhibition of SDF-1/CXCR4-induced epithelial-mesenchymal transition by kisspeptin-10. Breast Cancer Res Treat. 2015;152(1):41-50.

45. Dwinell MB, Ogawa $H$, Barrett KE, Kagnoff MF. SDF-1/CXCL12 regulates CAMP production and ion transport in intestinal epithelial cells via CXCR4. Am J Physiol Gastrointest Liver Physiol. 2004;286:G844-50.

46. Billadeau DD1, Chatterjee S, Bramati P. Sreekumar R, Shah V, Hedin K, et al. Characterization of the CXCR4 signaling in pancreatic cancer cells. Int J Gastrointest Cancer. 2006:37(4):110-9.

47. Wang M, Zhou A, An T, Kong L, Yu C, Liu J, et al. N-Hydroxyphthalimide exhibits antitumor activity by suppressing mTOR signaling pathway in BT-20 and LoVo cells. J Exp Clin Cancer Res. 2016;35:41.

48. Chen B, Tan Z, Gao J, Wu W, Liu L, Jin W, et al. Hyperphosphorylation of ribosomal protein $\mathrm{S} 6$ predicts unfavorable clinical survival in non-small cell lung cancer. J Exp Clin Cancer Res. 2015;34:126,

49. Delgado-Martín C, Escribano C, Pablos JL, Riol-Blanco L, RodríguezFernández JL. Chemokine CXCL12 uses CXCR4 and a signaling core formed by bifunctional Akt, extracellular signal-regulated kinase (ERK)1/2, and mammalian target of rapamycin complex 1 (mTORC1) proteins to control chemotaxis and survival simultaneously in mature dendritic cells. J Biol Chem. 2011;286(43):37222-36.

50. Liu F, Du ZY, He JL, Liu XQ, Yu QB, Wang YX. FTH1 binds to Daxx and inhibits Daxx-mediated cell apoptosis. Mol Biol Rep. 2012;39(2):873-9.

51. Buranrat $B$, Connor JR. Cytoprotective effects of ferritin on doxorubicininduced breast cancer cell death. Oncol Rep. 2015:34(5):2790-6.

52. Cheng HT, Yen CJ, Chang CC, Huang KT, Chen KH, Zhang RY, Lee PY, Miaw SC, Huang JW, Chiang CK, Wu KD, Hung KY. Ferritin heavy chain mediates the protective effect of heme oxygenase-1 against oxidative stress. Biochim Biophys Acta. 2015;1850(12):2506-17.

53. Abt AC, Meucci O. Regulation of neuronal ferritin heavy chain, a new player in opiate-induced chemokine dysfunction. Neuroimmune Pharmacol. 2011;6(4):466-76.

54. Nash B, Meucci O. Functions of the Chemokine receptor CXCR4 in the central nervous system and its regulation by $\mu$-Opioid receptors. Int Rev Neurobiol. 2014;118:105-28.

55. Roccaro AM, Mishima Y, Sacco A, Moschetta M, Tai YT, Shi J, et al. CXCR4 regulates extra-Medullary myeloma through epithelial-Mesenchymaltransition-like transcriptional activation. Cell Rep. 2015;12(4):622-35.

56. Sengupta R, Burbassi S, Shimizu S, Cappello S, Vallee RB, Rubin JB, et al. Morphine increases brain levels of Ferritin heavy chain leading to inhibition of CXCR4-mediated survival signaling in neurons. J Neurosci. 2009;29(8): 2534-44.

57. Huang M, Li Y, Zhang H, Nan F. Breast cancer stromal fibroblasts promote the generation of CD44+CD24- cells through SDF-1/CXCR4 interaction. J Exp Clin Cancer Res. 2010;29:80.

58. Liu Y, Ji R, Li J, Gu Q, Zhao X, Sun T, et al. Correlation effect of EGFR and CXCR4 and CCR7 chemokine receptors in predicting breast cancer metastasis and prognosis. J Exp Clin Cancer Res. 2010;29:16

59. Dunussi-Joannopoulos K, Zuberek K, Runyon K, Hawley RG, Wong A Erickson J, et al. Efficacious immunomodulatory activity of the chemokine stromal cell-derived factor 1 (SDF-1): local secretion of SDF-1 at the tumor site serves as T-cell chemoattractant and mediates T-cell-dependent antitumor responses. Blood. 2002;100(5):1551-8. 